\title{
Review
}

Guangda Xu, Peng Song* and Lixin Xia*

\section{Examples in the detection of heavy metal ions based on surface-enhanced Raman scattering spectroscopy}

https://doi.org/10.1515/nanoph-2021-0363

Received July 11, 2021; accepted October 15, 2021;

published online November 8, 2021

\begin{abstract}
Heavy metals have been widely applied in industry, agriculture, and other fields because of their outstanding physics and chemistry properties. However, heavy metal pollution is inevitable in the process of mass production and emission. Heavy metal ions will cause irreversible harm to the human body and other organisms due to their nondegradable nature even at low concentrations of exposure and ingestion. Therefore, it is of great significance for human health and ecological environment to develop high accuracy and sensitivity as well as stable techniques for detecting heavy metal ions. In recent years, surface-enhanced Raman scattering (SERS) spectroscopy has been regarded as a promising new technique for the determination of trace heavy metal ions on account of its special fingerprint identification capability, high sensitivity, rapid detection ability, and simple operation. This review summarized in detail the basic principles and strategies for detecting mercury ions, copper ions, arsenic ions, zinc ions, cadmium ions, lead ions, and chromium (VI) ions as well as the current challenges and future trends for the determination of heavy metal ions based on SERS technology.
\end{abstract}

Keywords: heavy metal ions; nanoparticles; rapid detection; SERS substrate; surface-enhanced Raman scattering spectroscopy.

\footnotetext{
*Corresponding authors: Peng Song, College of Physics, Liaoning University, Shenyang 110036, China, E-mail: songpeng@Inu.edu.cn; and Lixin Xia, College of Chemistry, Liaoning University, Shenyang 110036, China; and Yingkou Institute of Technology, Yingkou 115014, China, E-mail: lixinxia@lnu.edu.cn. https://orcid.org/0000-00033093-0068 (P. Song)

Guangda Xu, College of Chemistry, Liaoning University, Shenyang 110036, China
}

\section{Introduction}

Heavy metal ion pollution has become more and more serious with the rapid development of the economy in recent years. The health of organisms and the ecological balance of the environment are seriously threatened by the inability of heavy metal ions to degrade themselves. Therefore, the detection of heavy metal ions has become a research hotspot.

Heavy metals generally refer to metals with an atomic weight greater than 63.5 and a density greater than $5.0 \mathrm{~g} / \mathrm{cm}^{3}$ [1]. To date, more than 40 kinds of heavy metals such as gold $(\mathrm{Au})$, silver $(\mathrm{Ag})$, mercury $(\mathrm{Hg})$, copper $(\mathrm{Cu})$, zinc $(\mathrm{Zn})$, cadmium $(\mathrm{Cd})$, chromium (Cr), arsenic (As), and lead $(\mathrm{Pb})$, which are the most common in our daily life have been found in the environment. People usually believe that the heavy metal ions that exist naturally in the natural environment will not threaten the human body and the environment. However, the heavy metal content in rivers, lakes, and soil can exceed the standard with the acceleration of industrialization [2]. Once concentrated in water sources or plants and animals, these heavy metal ions can easily be amplified through the food chain, accumulating hundreds of times and eventually entering the human body [3]. When some heavy metal ions enter the human body, they interact strongly with proteins and enzymes that cannot be metabolized by the human body, and eventually, cause the organic matter in the body to lose biological activity [4]. In addition, heavy metal ions in the body can accumulate in certain organs and cause poisoning. Patients with mild poisoning may show symptoms such as dizziness, weakness of limbs, and memory loss. Severe cases can lead directly to breathing difficulties, acute kidney failure, and possibly even cancer [5-7]. The United States Environmental Protection Agency (USEPA) has stipulated a maximum concentration in drinking water for heavy metals, such as $2 \mathrm{ppb} \mathrm{Hg}, 1.3 \mathrm{ppm} \mathrm{Cu}, 10 \mathrm{ppb}$ As, $15 \mathrm{ppb} \mathrm{Pb}$, $5 \mathrm{ppb} C d$ and $100 \mathrm{ppb} \mathrm{Cr}$, respectively [8].

In view of the harm by the above heavy metals to the environment and the human body, the detection and removal of heavy metal ions has been widely studied by 
scientists. There are many traditional methods for the detection of heavy metal ions which are mainly divided into three categories (Table 1): spectroscopic, chromatographic, and electrochemical $[9,10]$ analysis (EC). Spectroscopic assays include atomic absorption spectroscopy (AAS) [11], atomic emission spectroscopy (AES) [12], atomic fluorescence spectroscopy (AFS) [13], inductively coupled plasmamass spectrometry (ICP-MS) [14], colorimetry [15, 16], and fluorescence spectroscopy [17, 18], among others. The main methods of chromatography are gas chromatography (GC) [19] and high-performance liquid chromatography (HPLC) [20]. Although these methods can achieve highly sensitive detection for heavy metal ions, they also have some disadvantages. For example, according to China's standard for the determination of heavy metal (HJ597-2011), $0.06 \mu \mathrm{g} / \mathrm{L}$ of total $\mathrm{Hg}$ in drinking water can be detected using AAS with microwave digestion when sampling volume is $25 \mathrm{~mL}$. However, it needs multiple sample preconcentration processing and expensive instruments. At this time, there is an urgent need for a simple, highly sensitive, and rapid technique for sensing heavy metal ions.

In the last few years, surface-enhanced Raman scattering (SERS) spectroscopy has been widely used in biomedicine, environmental monitoring, and food security due to its advantages of ultrahigh sensitivity, short response time, good selectivity, simple operation, and rich spectral fingerprint information [21, 22]. More and more researchers have used SERS technology to detect and quantitatively or semiquantitatively analyze heavy metal ions such as $\mathrm{Hg}^{2+}$, $\mathrm{Cu}^{2+}, \mathrm{Cd}^{2+}, \mathrm{Pb}^{2+}, \mathrm{Zn}^{2+}, \mathrm{As}^{3+}$, and $\mathrm{Cr}^{6+}$ in various environments [23-30]. Furthermore, some reviews describing SERS applications in various fields have been reported. For instance, $\mathrm{Wu}$ et al. reviewed SERS sensors for food safety and environmental monitoring [31]. Jwa-Min Nam's research group summarized the application of SERS in the detection of hazardous chemicals in different phases and matrices with various nanostructures [32]. In 2020, Ozaki et al. published a comprehensive overview of the detection of inorganic ions from the perspective of SERS [33]. Recently, Sun et al. summarized the fundamentals and recent applications in nondestructive food detection with flexible SERS substrates [34]. In this review, we present an in-depth discussion on the principles, strategies, challenges, and future development of SERS in detecting heavy metal ions.

\section{The introduction of SERS}

SERS: Raman spectroscopy is a widely used molecular recognition technology. Its scattering cross-section is only $10^{-6}$ and $10^{-14}$ of infrared and fluorescence spectroscopies
[35], respectively, which greatly limits its application in trace analysis and interface science. It was not until 1973 that Fleischmann et al. found that the Raman signal of the pyridine molecule on the surface of a rough silver electrode was about $10^{6}$ times stronger than that in the solution; the surface-enhanced Raman phenomenon was discovered [36]. Subsequently, the rapid development of SERS technology led to it being widely applied in the fields of surface adsorption [37], chemical and biological sensors [38], medical detection and analysis [39], interface chemistry, and catalytic reaction [40]. At present, the SERS mechanism generally agreed by the academic community mainly includes the electromagnetic (EM) enhancement mechanism and chemical enhancement (CE) mechanism.

In the EM enhancement theory, the enhancement of the local EM field caused by surface plasmon resonance (SPR) is considered to be the most important contribution [41]. The SPR model notes that under laser irradiation, electrons and photoelectrons on and near the metal surface will vibrate [42]. According to the conservation of momentum, the rough metal surface can excite plasmons, so when the laser excites the roughened SERS substrate surface, the plasmons on the surface of the material can be excited to a high-energy state and then coupled with the electric field of the light wave. In this way, resonance can occur, so that the EM field of the SERS substrate is enhanced. Once the molecule enters the region where the electric field is enhanced, its Raman intensity is greatly enhanced.

However, the EM enhancement theory cannot explain the phenomena related to chemical properties, so the CE mechanism was proposed to explain the phenomena associated with chemical adsorption [38]. The analysis of the CE mechanism has the following aspects: (1) The active SERS substrate forms a chemical bond with the target molecule on the adsorption surface, and there is a charge transfer (CT) phenomenon between the substrate and the molecule. The lowest unoccupied molecular orbital (LUMO) and highest occupied molecular orbital (HOMO) of the molecule become wider apart, and the polarization rate of the system hardly changed. (2) The target molecule on the surface of the active SERS substrate and the surrounding adsorbed atoms form a complex to produce resonance enhancement. The LUMO and HOMO orbitals of the adsorbed molecular system are different, and resonance is achieved in the visible light region. (3) The laser used in the detection induces a CT phenomenon between the target molecule and the SERS substrate, resulting in a resonance effect, which is mainly determined by the energy difference between the Fermi level of the substrate and the LUMO or HOMO of the target molecule. When the difference matches the energy of the 
Table 1: Several different methods to detect heavy metals.

\begin{tabular}{|c|c|c|c|c|c|}
\hline Methods & Principle & Features & Metal & Detect limit & Ref. \\
\hline AAS & $\begin{array}{l}\text { It is based on the ground state atom of the } \\
\text { measuring element and the characteristic } \\
\text { resonant radiation of its corresponding atom } \\
\text { to produce resonance absorption, and its } \\
\text { absorbance is proportional to the ground } \\
\text { state atomic concentration, so as to realize } \\
\text { the qualitative and quantitative analysis of } \\
\text { the measuring element }\end{array}$ & $\begin{array}{l}\text { High accuracy, good selectivity, } \\
\text { strong anti-interference ability, } \\
\text { but complex preprocessing }\end{array}$ & $\begin{array}{l}\mathrm{Pb}, \mathrm{Cd} \text {, and } \\
\mathrm{Hg}\end{array}$ & $\begin{array}{l}\text { Passed the criteria set by } \\
\text { Commission Regulation } \\
\text { (EU) No 836/2011 }\end{array}$ & [11] \\
\hline AES & $\begin{array}{l}\text { After the gaseous atoms or ions are excited, } \\
\text { the outer electrons transfer and radiate the } \\
\text { light of different characteristic wavelengths, } \\
\text { so the qualitative and quantitative analysis of } \\
\text { the elements is realized according to the } \\
\text { wavelength and intensity of the character- } \\
\text { istic spectrum }\end{array}$ & $\begin{array}{l}\text { High precision, and accuracy, } \\
\text { wide linear range but complex } \\
\text { preprocessing }\end{array}$ & $\begin{array}{l}\mathrm{Hg}, \mathrm{Cd} \text {, and } \\
\mathrm{Pb}\end{array}$ & $\begin{array}{l}8.0 \mu \mathrm{g} / \mathrm{kg}, 17.8 \mu \mathrm{g} / \mathrm{kg} \text {, } \\
\text { and } 3.5 \mathrm{mg} / \mathrm{kg}\end{array}$ & [12] \\
\hline AFS & $\begin{array}{l}\text { It is an atomic spectroscopy analysis method } \\
\text { that uses high-energy excited atoms to emit } \\
\text { characteristic wavelengths of fluorescence } \\
\text { during the de-excitation process for quanti- } \\
\text { tative detection of elements }\end{array}$ & $\begin{array}{l}\text { High accuracy and reliability, } \\
\text { but complex preprocessing and } \\
\text { expensive equipment }\end{array}$ & $\begin{array}{l}\mathrm{Hg}, \mathrm{As}, \mathrm{Pb} \text {, } \\
\text { and } \mathrm{Cd}\end{array}$ & $5,68,40$, and $3 \mathrm{ng} / \mathrm{L}$ & [13] \\
\hline ICP-MS & $\begin{array}{l}\text { It is a highly developed elemental analysis } \\
\text { technology formed by inductively coupled } \\
\text { plasma as the excitation light source com- } \\
\text { bined with mass spectrometry }\end{array}$ & $\begin{array}{l}\text { High accuracy and sensitivity, } \\
\text { but complex preprocessing and } \\
\text { expensive equipment }\end{array}$ & $\begin{array}{l}\mathrm{Cd}, \mathrm{Pb}, \mathrm{As} \text {, } \\
\text { and } \mathrm{Hg}\end{array}$ & $\begin{array}{l}0.002,0.01,0.02, \text { and } \\
0.01 \mathrm{mg} / \mathrm{kg}\end{array}$ & [14] \\
\hline EC & $\begin{array}{l}\text { It is an instrumental analysis method based } \\
\text { on the relationship between the electrical } \\
\text { parameters such as the potential at the } \\
\text { interface of the electrode and the concen- } \\
\text { tration of the measured substance }\end{array}$ & $\begin{array}{l}\text { Simple operation, fast analysis, } \\
\text { high sensitivity, but low accu- } \\
\text { racy and reproducibility }\end{array}$ & $\begin{array}{l}\mathrm{Pb}, \mathrm{Cd} \text {, and } \\
\mathrm{Zn} \\
\mathrm{Cu}, \mathrm{Pb} \text {, and } \\
\mathrm{Cd}\end{array}$ & $\begin{array}{l}0.04,0.02 \text {, and } 0.05 \mu \mathrm{g} / \mathrm{L} \\
0.10,0.14 \text {, and } 0.16 \mu \mathrm{M}\end{array}$ & [10] \\
\hline Colorimetry & $\begin{array}{l}\text { It is a method to the analysis of the substance } \\
\text { by comparing or measuring the color depth of } \\
\text { the colored substance solution }\end{array}$ & $\begin{array}{l}\text { Simple and rapid analysis, but } \\
\text { low sensitivity and accuracy }\end{array}$ & $\begin{array}{l}\mathrm{Pb}, \mathrm{Cd}, \mathrm{Sb} \text {, } \\
\text { and } \mathrm{Hg} \\
\mathrm{Hg} \text { and } \mathrm{Pb}\end{array}$ & $-^{\mathrm{a}}$ & [15] \\
\hline $\begin{array}{l}\text { Fluorescence } \\
\text { method }\end{array}$ & $\begin{array}{l}\text { The substance is in an excited state after } \\
\text { being irradiated by ultraviolet light, and } \\
\text { when the excited state returns to the ground } \\
\text { state, it can emit specific fluorescence to } \\
\text { realize the analysis of the substance }\end{array}$ & $\begin{array}{l}\text { Simple pretreatment, high } \\
\text { sensitivity, but complex syn- } \\
\text { thesis process }\end{array}$ & $\begin{array}{l}\mathrm{Pb}, \mathrm{Cu}, \mathrm{Cd} \text {, } \\
\text { and } \mathrm{Ni} \\
\mathrm{Pb}, \mathrm{Cd} \text {, and } \\
\mathrm{Hg}\end{array}$ & $\begin{array}{l}0.01,0.1,0.012 \text {, and } \\
0.1 \mu \mathrm{M} \\
-\end{array}$ & [17] \\
\hline GC & $\begin{array}{l}\text { It is a chromatographic technique that sepa- } \\
\text { rates and analyzes compounds that are easy } \\
\text { to volatilize but do not decompose }\end{array}$ & $\begin{array}{l}\text { High sensitivity, rapid analysis } \\
\text { but complicated the operation }\end{array}$ & $\begin{array}{l}\mathrm{Hg} \text { and } \\
\text { organic } \\
\text { mercury }\end{array}$ & $10 \mathrm{ng} / \mathrm{g}$ & [19] \\
\hline HPLC & $\begin{array}{l}\text { It is based on the difference between the af- } \\
\text { finity of each component in the mixture to the } \\
\text { two phases to achieve the separation of } \\
\text { substances }\end{array}$ & $\begin{array}{l}\text { Wide application range, high } \\
\text { sensitivity, but the complicated } \\
\text { operation }\end{array}$ & $\mathrm{Hg}$ & $0.8 \mathrm{ppb}$ & [20] \\
\hline
\end{tabular}

${ }^{\mathrm{a}}$ Not mentioned.

laser, an enhancement effect will be produced [43]. The above three enhancement mechanisms have an effect on the enhancement of SERS with the change of the polarizability, so the CT theory has a certain basis and is widely recognized. A large number of experimental results show that the EM enhancement or CE mechanism alone cannot explain all SERS phenomena, and these two mechanisms often coexist.
Raman signal molecules: As a marker for SERS detection, Raman signaling molecules are usually divided into two categories: the first category is molecules with $-\mathrm{SH}$ or $-\mathrm{NH}_{2}$ functional groups such as 4-aminothiophenol (4-ATP), 4-mercaptobenzoic acid (4-MBA), and 4-mercaptopyridine (4-MPy), which own a strong affinity to metal substrates through forming chemical bonds; the second category is 
some dye molecules with charged such as rhodamine $6 \mathrm{G}$ (R6G), rhodamine B (RB), and malachite green (MG), which combine with the metal substrate through electrostatic attraction.

Raman excitation wavelength: The most common excitation wavelengths in SERS detection are mainly 532, 633, 785, and $1064 \mathrm{~nm}$. As the excitation wavelength increases, the energy of the laser gradually decreases, which usually results in a decrease in Raman intensity. However, high-energy lasers may damage the sample and produce unanticipated fluorescence interference. Excitation at longer wavelengths ( 785 and $1064 \mathrm{~nm}$ ) is able to avoid the above disadvantages. In addition, when the plasmon band generated by noble metal substrates is near the excitation wavelength, the produced resonance effect can effectively enhance SERS activity [44]. Therefore, selecting the appropriate excitation wavelength in SERS detection is a benefit to obtain the optimal Raman signal.

Density functional theory (DFT): As a method to study the electronic structure of multi-electron systems, DFT is widely applied in the fields of condensed matter physical computational materials science and computational chemistry [45]. Because of the outstanding ability of DFT for simulating Raman and SERS spectra and analyzing the adsorption behavior of molecules on the substrate, it is popular in SERS detection and has gradually become one of the indispensable theoretical analysis tools.

\section{Determination of heavy metal ions}

\subsection{Detection of mercury ions}

Mercury and its compounds are released into the environment in large quantities and eventually accumulate in the human body due to being nonbiodegradable through the natural mercury cycle, which causes irreversible damage to the human body [46]. Studies have linked mercury poisoning to neurological disorders, arrhythmias, immune system dysfunction, kidney damage, bronchitis, pneumonia, and even respiratory failure [4]. Many articles based on SERS methods to determine mercury ions have been reported so far [47-53].

Mercury ions interact with SERS-active molecular recognition elements (MREs) [31]. Cai's group designed a new strategy to recognize mercury ions in an aqueous solution through an electrophilic substitution reaction using Au-ordered nanorod arrays functionalized with 4-mercaptophenylboronic acid (4-MPBA) as SERS substrate
(Figure 1a) [54]. According to DFT, when mercury ions reacted with 4-MPBA, the characteristic peaks of the $\mathrm{C}-\mathrm{B}$ stretching vibration and $\mathrm{B}-\mathrm{OH}$ shear vibration disappeared completely, the peaks of $\mathrm{C}=\mathrm{C}$ stretching and breathing vibration modes of 4-MPBA blueshifted and the new peaks that were deemed to be $\mathrm{HgCl}$-affected benzene deformation and $\mathrm{C}-\mathrm{Hg}$ stretching vibration appeared synchronously. Based on the appearance and movement of peaks, $\mathrm{Hg}^{2+}$ ions were quantitatively analyzed from $10^{-5}$ to $10^{-10} \mathrm{M}$ with a high detection sensitivity of $0.1 \mathrm{nM}$. Yang et al. proposed a novel gold nanoparticles/e indium tin oxide (AuNPs/ITO) film decorated with 4-MPy which was not only used as a Raman reporter but also a $\mathrm{Hg}^{2+}$ ions capture agent to form 4-MPy/ AuNPs/ITO chips (Figure 1b) [55]. Once added, $\mathrm{Hg}^{2+}$ ions bond specifically to nitrogen atoms and changed the electron distribution on the pyridine rings, leading to a reorientation of the 4-MPy molecules and an increase of the intensity of the peak at $1093 \mathrm{~cm}^{-1}$, which was verified by DFT calculations. The limit of detection (LOD) was as low as 1 ppt. In 2016, a novel readout approach on account of a peculiar phenomenon - the SERS frequency-shift method that had the advantages of smaller standard deviation and higher accuracy compared with the traditional quantitative determination method based on the SERS intensity (Figure 1c) was introduced [56]. When $\mathrm{Hg}^{2+}$ ions were added to a self-assembled silver film that was modified with dimethyldithiocarbamic acid sodium salt, they bond specifically to the sulfur atoms, inducing a shift in frequency to higher wavenumbers for quantitative analysis of mercury ions and organic mercury with a LOD of $10^{-8} \mathrm{M}$. More importantly, the frequency-shift-based method provided new insight into the determination of heavy metal ions.

"Turn-on" mode. In the "turn-on" mode, the characteristic signal peaks of SERS reporters were significantly amplified with the increase of metal ions' concentration. There is no doubt that the most common mode of turn-on is the DNA/oligonucleotides connection mode based on the thymine- $\mathrm{Hg}^{2+}$-thymine $\left(\mathrm{T}-\mathrm{Hg}^{2+}-\mathrm{T}\right)$ coordination chemistry. Many research groups have proposed new strategies to detect $\mathrm{Hg}^{2+}$ ions utilizing this method. For instance, Kuang et al. self-assembled two T-rich complementary singlestranded DNA (ssDNA) molecules on different gold nanostars (GNS) that were labeled with 4-ATP probes first (Figure 2a) [57]. In the presence of $\mathrm{Hg}^{2+}$, two ssDNA were matched to double-stranded DNA (dsDNA) because of the formation of a $\mathrm{T}-\mathrm{Hg}^{2+}-\mathrm{T}$ structure, which led to the dimerization of nanostars. Abundant hot spots were generated because of the proximity of nanostars, which significantly increased the Raman intensity of 4-ATP and reached a LOD of $0.8 \mathrm{ppt}$. Afterward, they made use of similar principles to self-assemble nanochains and trimer 
(a)

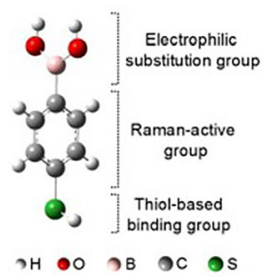

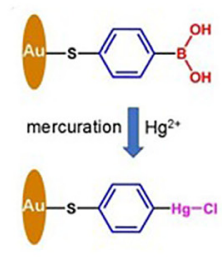

(b)
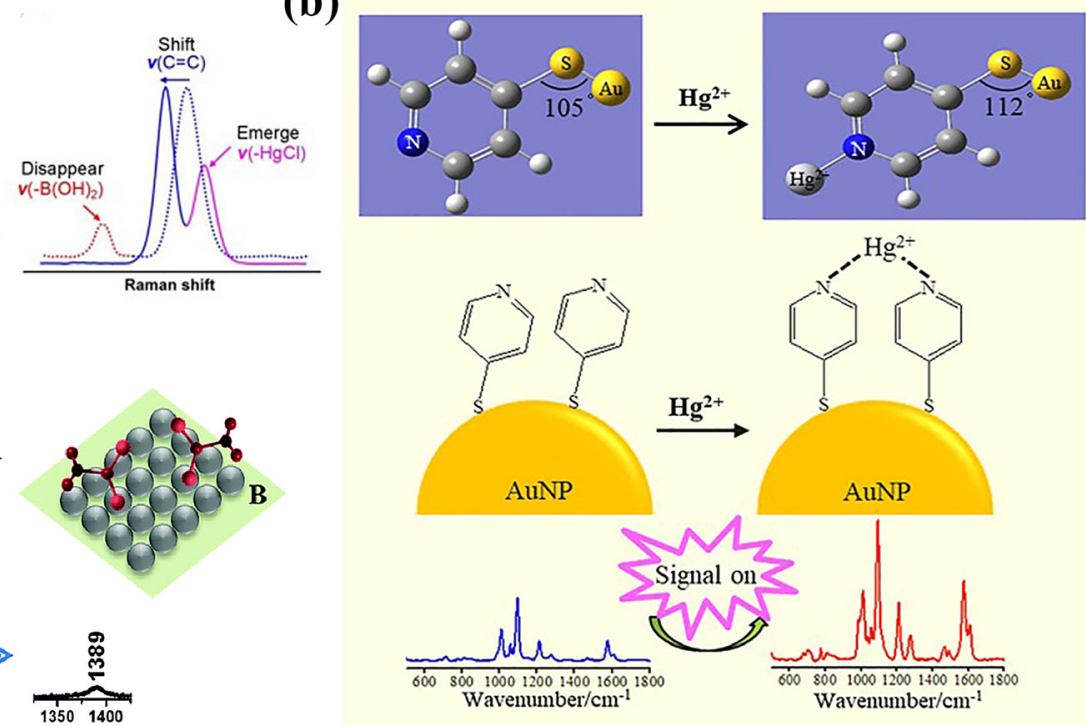

(c)

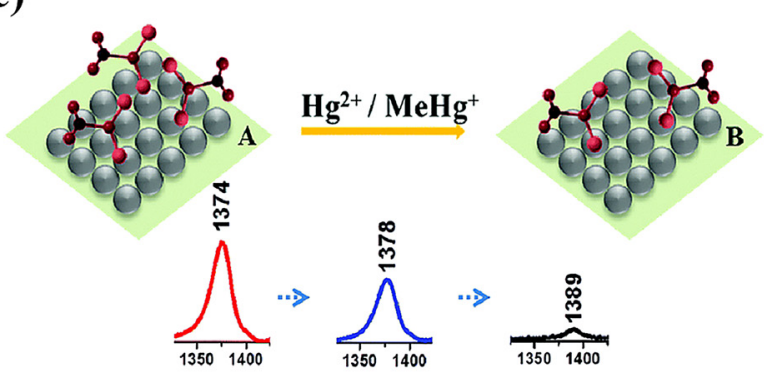

Figure 1: Detection of $\mathrm{Hg}^{2+}$ through SERS-active MREs reacting with $\mathrm{Hg}^{2+}$ ions.

(a) Recognizing $\mathrm{Hg}^{2+}$ ions through electrophilic substitution reaction between $\mathrm{Hg}^{2+}$ and 4-MPBA [54]. (b) Recyclable 4-MPy/AuNPs/ITO chips for $\mathrm{Hg}^{2+}$ ions detection [55]. (c) SERS frequency-shift method to determine $\mathrm{Hg}^{2+}$ or $\mathrm{MeHg}^{+}$via binding with dimethyldithiocarbamic acid sodium salt (DASS) [56].

structures to detect $\mathrm{Hg}^{2+}$ ions and achieved encouraging results [58, 59]. Furthermore, some special structures such as sandwich structure and hairpin structure have been successfully developed based on the $\mathrm{T}-\mathrm{Hg}^{2+}-\mathrm{T}$ structure. Chung's group reported an assay in which a gold microshell functionalized with DNA aptamer served as the SERS substrate and tetramethylrhodamine (TAMRA) was employed as the SERS reporter (Figure $2 \mathrm{~b}$ ) [60]. The signal of the SERS probe was dramatically enhanced due to the DNA aptamer being induced into a hairpin structure which brought the TAMRA closer to the gold microshell surface in the presence of $\mathrm{Hg}^{2+}$. The achieved LOD was $50 \mathrm{nM}$. As a consequence of the operational complexity of modifying tags on DNA, the label-free SERS probe was preferred by researchers. Huang et al. put forward a new label-free SERS sensor (Figure 2c) [61]. In their design, the DNA aptamer was anchored on the surface of $\mathrm{SiO}_{2} @ \mathrm{Au}$ core/shell nanoparticles. It was worth noting that the consecutive thymines worked as the $\mathrm{Hg}^{2+}$ ions capture agent, and the guanine $(\mathrm{G})$ and adenine (A) base pairs served as the signal reporters in the DNA aptamer which consisted of two portions. Owing to the formation of the $\mathrm{T}-\mathrm{Hg}^{2+}-\mathrm{T}$ structure between mercury ions and thymines on adjacent DNA strands, DNA molecules took a vertical orientation, resulting in the change of Raman intensity ratio $I\left(660 \mathrm{~cm}^{-1}\right) / I\left(736 \mathrm{~cm}^{-1}\right)$, which provided the basis for quantitative and selective analysis of $\mathrm{Hg}^{2+}$ ions within a wide concentration range from $10^{-8}$ to $10^{-3} \mathrm{M}$. In addition to the $\mathrm{T}-\mathrm{Hg}^{2+}-\mathrm{T}$ mode, other structures are also applied to trigger the SERS substrate aggregation to turn on the signal, such as cysteine [24], polyaromatic ligands [51], and so on. Furthermore, Kang and coworkers took advantage of the interaction between mercury ions and terminal alkynes of 1,4-diethynylbenzene (DEB) to form the $\mathrm{C} \equiv \mathrm{C}-\mathrm{Hg}-\mathrm{C} \equiv \mathrm{C}$ linkage structure, shortening the distance of silver nanoparticles (AgNPs) embellished with DEB (Figure 2d) [62]. A unique vibrational peak of $\mathrm{C} \equiv \mathrm{C}-\mathrm{Hg}-\mathrm{C} \equiv \mathrm{C}$ at $2146 \mathrm{~cm}^{-1}$, located in the Raman silent section $\left(1900-2500 \mathrm{~cm}^{-1}\right)$, was conducive to eliminating the background interference and quantitatively detecting $\mathrm{Hg}^{2+}$. The Raman intensity of $\mathrm{C} \equiv \mathrm{C}-\mathrm{Hg}-\mathrm{C} \equiv \mathrm{C}$ was enhanced with the increase in the concentration of $\mathrm{Hg}^{2+}$ ions and a low detection limit (0.8 nM) was calculated.

"Turn-off" mode. In the closed mode, the most common strategy is to keep the SERS reporter away from the plasmonic metal substrate. For example, Wang et al. constructed a stable and repeatable SERS sensor which consisted of an Ag nanorods array that was modified with a single-strand oligonucleotide probe (Figure 3a) [63]. The single-strand oligonucleotide comprised 15 thymines with a thiol group at the $5^{\prime}$-terminal and a Cyanine 5 (Cy5) reporter at the $3^{\prime}$-end. Under normal circumstances, most oligonucleotides are in a relaxed state, and the Cy5 reporter at the $3^{\prime}$-end could be placed on the SERS substrate due to the flexibility of 
(a)

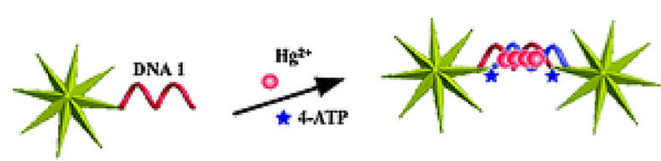

次

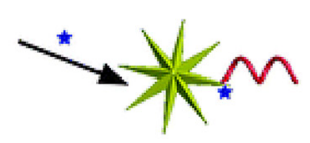

(c)

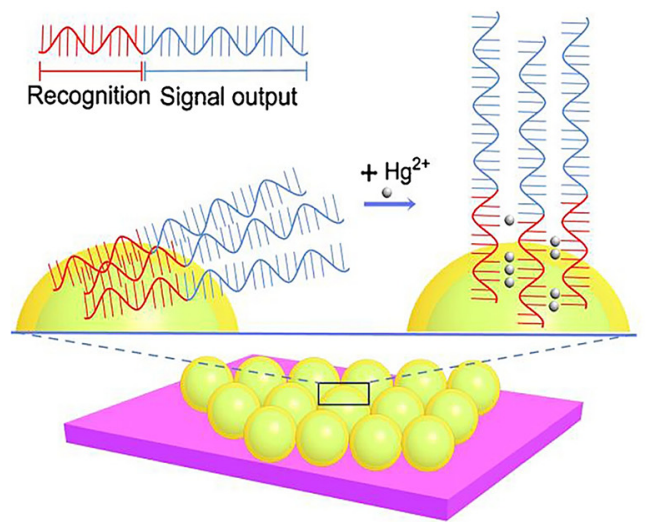

(b)

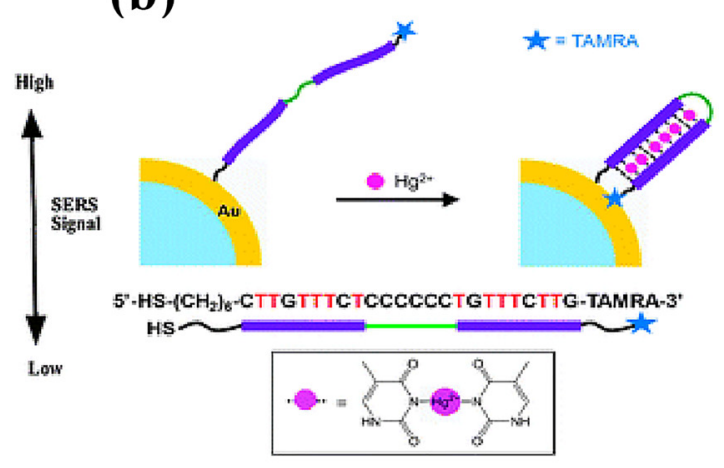

(d)

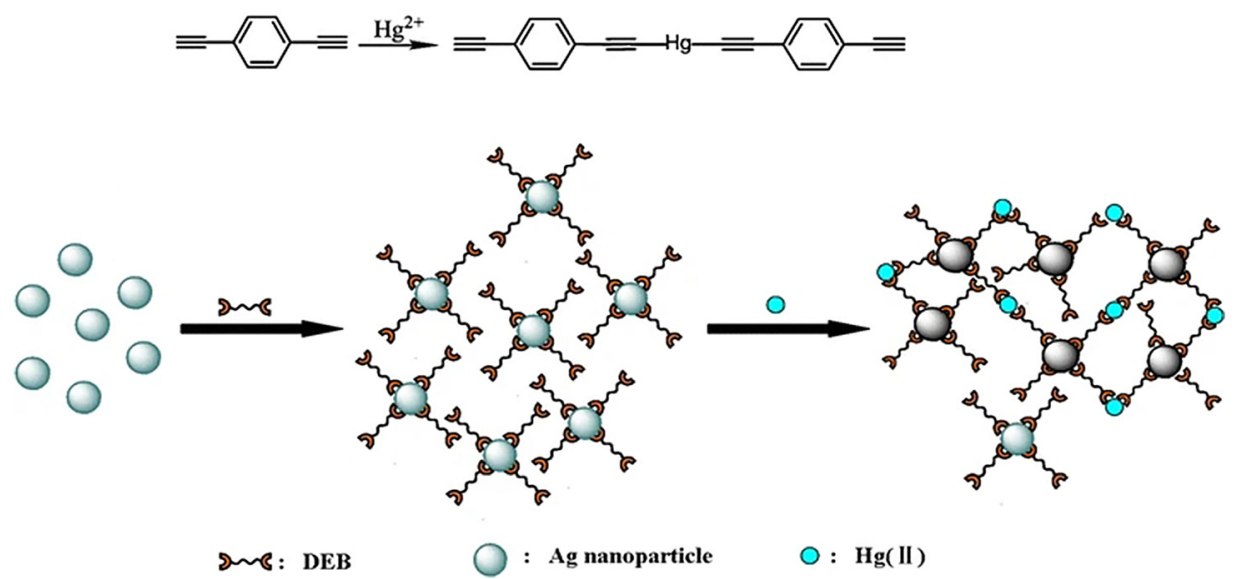

Figure 2: Schematic diagram of the detection of $\mathrm{Hg}^{2+}$ ions based on "turn-on" mode.

(a) Self-assembly gold nanostars aggregated to dimers based on the $\mathrm{T}-\mathrm{Hg}^{2+}-\mathrm{T}$ structure [57]. (b) The DNA aptamer was induced into a hairpin structure [60]. (c) The DNA aptamer ad sorbed vertically on the surface of $\mathrm{SiO}_{2} @ A$ u core/shell nanoparticles [61]. (d) $\mathrm{Hg}^{2+}$ ions connected to DEB to trigger the aggregation of AgNPs [62].

the single-chain structure. However, single-stranded oligonucleotides were converted into double-strand-like complexes that eventually tended to stand upright because of the formation of the $\mathrm{T}-\mathrm{Hg}^{2+}-\mathrm{T}$ coordination structure in the presence of $\mathrm{Hg}^{2+}$ ions. Therefore, $\mathrm{Cy} 5$ reporters were removed from the SERS substrate, accompanied by a decrease of signal intensity at $1468 \mathrm{~cm}^{-1}$. A low LOD $(0.16 \mathrm{pM})$ was obtained. Figure $3 \mathrm{~b}$ unambiguously illustrates another working principle of the detection of $\mathrm{Hg}^{2+}$ ions [64]. First, the $\mathrm{CoFe}_{2} \mathrm{O}_{4} @ \mathrm{Ag}$ substrate which had high sensitivity and uniformity by the aggregation effect of the magnet was successfully synthesized through a multistep reaction, and 
ssDNA was labeled on the surface. Afterward, the singlewalled carbon nanotubes (SWCNTs), which acted as the Raman reporter, were transformed to $\mathrm{CoFe}_{2} \mathrm{O}_{4} @ \mathrm{Ag} @ s s D-$ NA@SWCNTs complexes through the $\pi-\pi$ interaction with the ssDNA. When thymines on ssDNA captured $\mathrm{Hg}^{2+}$ ions, the $\mathrm{T}-\mathrm{Hg}^{2+}-\mathrm{T}$ structure formed, leaving SWCNTs away from ssDNA, that is, away from the hot spots area of the SERS substrate. In their design, the SERS sensor determinated $\mathrm{Hg}^{2+}$ ions with a wide range from $1 \mathrm{pM}$ to $100 \mathrm{nM}$ and a LOD of $0.84 \mathrm{pM}$. In other cases, SERS-active probes dropped from the metal surface due to their stronger binding ability to $\mathrm{Hg}^{2+}$ ions than to noble metal. A femtomolar approach of detecting $\mathrm{Hg}^{2+}$ ions by utilizing silver-coated gold nanoparticles (Au@AgNPs) functionalized with 4,4'-dipyridyl (Dpy) was introduced by Du et al. (Figure 3c) [65]. When $\mathrm{Hg}^{2+}$ ions were added, the SERS signal of Dpy molecules was weakened because it was bound to $\mathrm{Hg}^{2+}$ ions and released from the metal surface. The detection limit was $10 \mathrm{fM}$. Similar work was reported in 2020 by Dou's group [66]. Furthermore, $\mathrm{Hg}^{2+}$ ions can also be reduced to zero-valent mercury and form complexes with plasmonic metals such as amalgam. In Wang's design, they presented a label-free method for rapid detection of $\mathrm{Hg}^{2+}$ within $2 \mathrm{~min}$ (Figure 3d) [67]. In the absence of $\mathrm{Hg}^{2+}$, Raman reporter molecules could be adsorbed on the metal surface via chemical bonds or physical adsorption and generated an intense SERS signal. When $\mathrm{Hg}^{2+}$ was present, they interacted with AgNPs including the complexation of $\mathrm{Hg}^{2+}$ ions with citrate and the reduction of $\mathrm{Hg}^{2+}$ ions in an

(a)

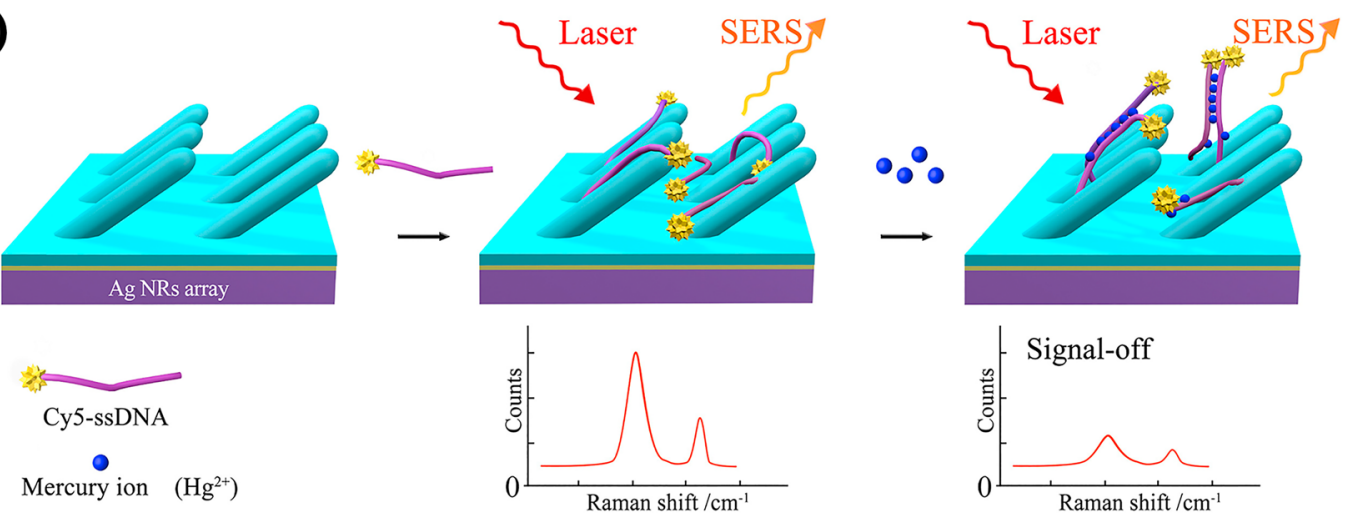

(b)

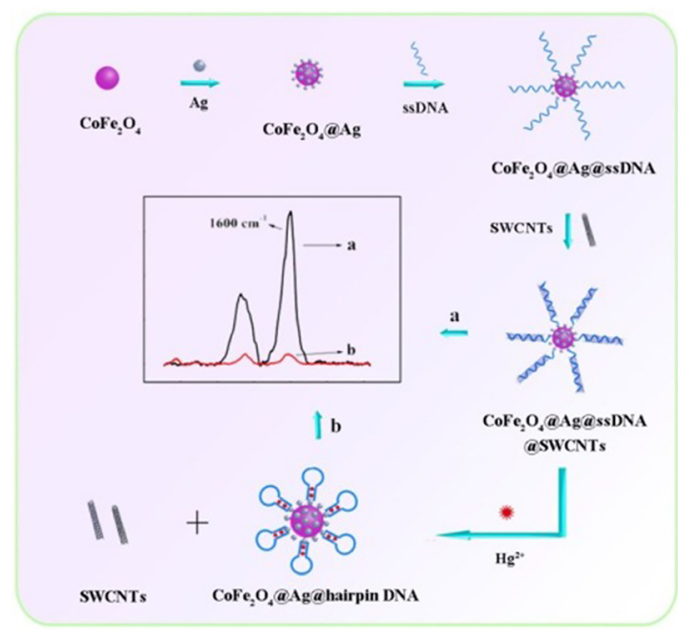

(c)

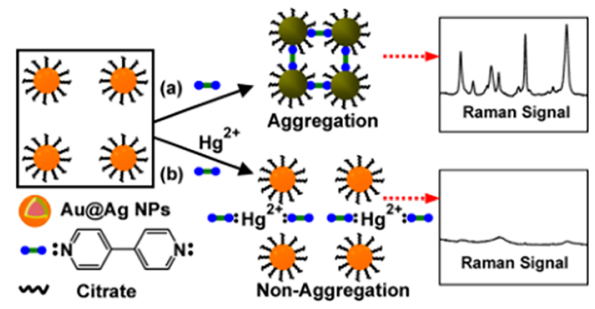

(d)

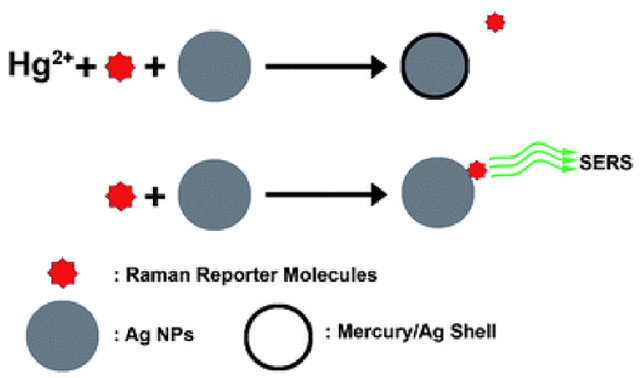

Figure 3: Schematic description of the detection of $\mathrm{Hg}^{2+}$ ions based on "turn-off" mode.

(a) Single-stranded oligonucleotides converted into double-stranded-like complexes with a vertical orientation [63]. (b) The SWCNTs stayed away from ssDNA because of the formation of the $\mathrm{T}-\mathrm{Hg}^{2+}-\mathrm{T}$ structure [64]. (c) Dpy molecules were bound to $\mathrm{Hg}^{2+}$ ions and released from the metal surface [65]. (d) $\mathrm{Hg}^{2+}$ ions were reduced to zero-valent mercury and formed an amalgam [67]. 
Table 2: The methods for detecting mercury ions based on SERS in recent years.

\begin{tabular}{|c|c|c|c|c|c|}
\hline SERS substrate & Raman reporter & Range & LOD & Comments & Ref. \\
\hline Au NRAs ${ }^{a}$ & 4-MPBA & $10^{-5}-10^{-10} M$ & $0.1 \mathrm{nM}$ & Sensitive, accurate, and anti-interference & [54] \\
\hline 4-MPy/AuNPs/ITO chip & 4-MPy & $\begin{array}{l}1.0 \mathrm{ppt}-100 \mathrm{ppb} \\
(4.99 \mathrm{pM}-0.49 \mu \mathrm{M})\end{array}$ & $1.0 \mathrm{ppt}(4.99 \mathrm{pM})$ & Stable, recyclable but not novel & [55] \\
\hline Self-assembled Ag film & DASS $^{b}$ & $10^{-3}-10^{-6} \mathrm{M}$ & $0.1 \mathrm{nM}$ & Novel, sensitive, and accurate & [56] \\
\hline GNS & 4-ATP & $\begin{array}{l}0.002-1 \mathrm{ppb} \\
(9.97 \mathrm{pM}-4.99 \mathrm{nM})\end{array}$ & $0.8 \mathrm{ppt}(3.99 \mathrm{pM})$ & Sensitive, reliable but complicated & [57] \\
\hline AuNPs & 4-NTP & $\begin{array}{l}0.001-0.5 p p b \\
(4.99 \mathrm{pM}-2.49 \mathrm{nM})\end{array}$ & $0.45 \mathrm{ppt}(2.24 \mathrm{pM})$ & Sensitive, reliable but complicated & [58] \\
\hline AuNPs & 4-ATP & $\begin{array}{l}0.002-0.5 \mathrm{ppb} \\
(9.97 \mathrm{pM}-2.49 \mathrm{nM})\end{array}$ & $2.44 \mathrm{ppt}(12.16 \mathrm{pM})$ & Sensitive, reliable but complicated & [59] \\
\hline Ag@AuNPs & TAMRA & - & $50 \mathrm{nM}$ & Selective but low sensitivity & [60] \\
\hline $\mathrm{SiO}_{2} @ A u N P s$ & Oligomers & $10^{-8}-10^{-3} \mathrm{M}$ & $10 \mathrm{nM}$ & Label-free, wide linear range but not accurate & [61] \\
\hline AgNPs & DEB & $1.1-61.2 \mathrm{nM}$ & $0.8 \mathrm{nM}$ & Simple, rapid but low reproducibility & [62] \\
\hline $\operatorname{AgNRs}^{d}$ & Cy5 & $1 \mathrm{pM}-1 \mu \mathrm{M}$ & $0.16 \mathrm{pM}$ & Sensitive, wide linear range but complicated & [63] \\
\hline $\mathrm{CoFe}_{2} \mathrm{O}_{4} @ \mathrm{AgNPs}$ & SWCNTS & $1 \mathrm{pM}-100 \mathrm{nM}$ & $0.84 \mathrm{pM}$ & Sensitive, selective but complicated & [64] \\
\hline Au@AgNPs & Dpy & $10^{-14}-10^{-10} \mathrm{M}$ & $10 \mathrm{fM}$ & Ultrasensitive, rapid and recyclable & [65] \\
\hline AgNPs & Dpy & $\begin{array}{l}1-100 \mathrm{ppb} \\
(4.99 \mathrm{nM}-0.49 \mu \mathrm{M})\end{array}$ & $0.1 \mathrm{ppb}(0.49 \mathrm{nM})$ & Not novel & [66] \\
\hline AgNPS & $C V, B G, B^{e}$ & - & $90.9 \mathrm{pM}$ & Simple, rapid but low reproducibility & [67] \\
\hline AgNPS & Acriflavine & $0.1-8.0 \times 10^{-7} \mathrm{M}$ & $1.4 \mathrm{nM}$ & Not novel & [68] \\
\hline
\end{tabular}

${ }^{\mathrm{a}} \mathrm{Au}$ ordered nanorod arrays (Au NRAs); ${ }^{\mathrm{b}}$ dimethyldithiocarbamic acid sodium salt crystal (DASS); ${ }^{\mathrm{c}} 4$-nitrothiophenol (4-NTP); ${ }^{\mathrm{d}} \mathrm{Ag}$ nanorods (AgNRs); ${ }^{e}$ violet (CV), Brilliant green (BG), ethidium bromide (EB).

amalgam. Once the amalgam was formed, Raman reporter molecules would stay away from the metal surface due to the decrease of SERS activity and the adsorption capacity influenced by the mercury/Ag shell structure. Taking advantage of an identical principle, Tian's team created AgNPs modified with acriflavine to recognize $\mathrm{Hg}^{2+}$ ions in water [68]. Table 2 summarizes the methods for detecting $\mathrm{Hg}^{2+}$ ions based on SERS in recent years.

\subsection{Detection of copper(II) ions}

Copper ion is a necessary trace element in the human body and plays an irreplaceable role in physiological regulation. Lack of copper ions will affect the normal metabolism, hematopoiesis, and other functions of cells, while excessive intake of copper ions can lead to neurological diseases such as Parkinson's and Alzheimer's diseases [69, 70]. Compared with mercury ions, copper ions detection based on SERS is much less reported. The determination of copper ions is mainly based on the coordination between copper ions and specific atoms such as nitrogen and oxygen, to achieve a change of Raman characteristic peaks or trigger the aggregation of metal nanoparticles to further quantitative analysis of copper ions.

Copper ions bonding with certain atoms. In 2012, Sarkar et al. exploited AuNPs functionalized with 2-mercaptobenzimidazole which served as both SERS-active MRE and Raman reporter [71]. When $\mathrm{Cu}^{2+}$ ions were added to the system, they combined with nitrogen atoms, resulting in a rise of the peak at $1407 \mathrm{~cm}^{-1}$ and a fall of the peak at $1451 \mathrm{~cm}^{-1}$. The detection limit was $15 \mu \mathrm{M}$. Moreover, an innovative scenario was built by Li's group (Figure 4a) [72]. The carboxyl and amino groups on the cysteine coated on the surface of GNS can specifically bind with copper ions. Based on this principle, copper ions in aqueous media were successfully identified according to the dramatic increase of $-\mathrm{COOH}$ peak given rise by the GNS aggregation with a LOD of $10 \mu$ M. Similarly, trimercaptotriazine (TMT) was also employed as the bridging molecule to recognize copper ions by combining with sulfhydryl and nitrogen atoms [73]. Notably, the TMT molecule can also be applied to detect mercury and cadmium ions [74]. Despite satisfactory results having been achieved, it was still urgent to establish more sensitive strategies. In recent years, polymer affinity agents have shown fantastic potential in detecting small biological molecules such as pesticides and biotoxins [75]. As a stabilizer and protective agent, polyvinylpyrrolidone (PVP) plays a significant role in the nucleation and growth stage of metal nanoparticles [76]. Figure $4 \mathrm{~b}$ explains the mechanism by which PVP modified AgNPs detect copper ions [77]. PVP generated a series of characteristic peaks through the interaction between oxygen atoms and AgNPs. When copper ions existed, copper ions linked with $\mathrm{N}$ and $\mathrm{O}$ atoms of PVP, 
(a)

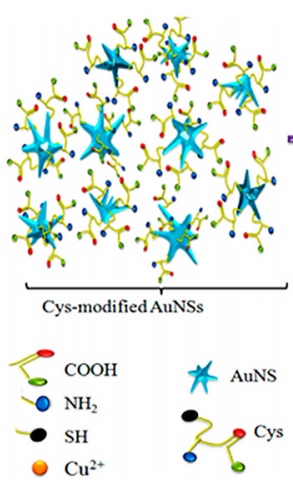

(c)

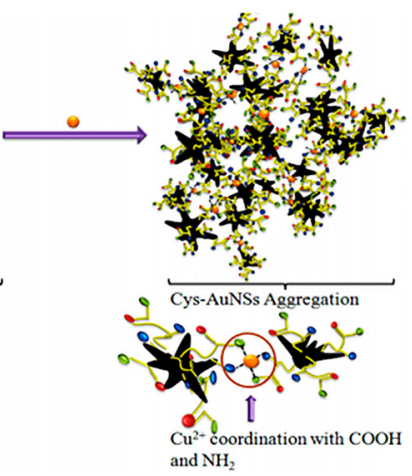

(b)

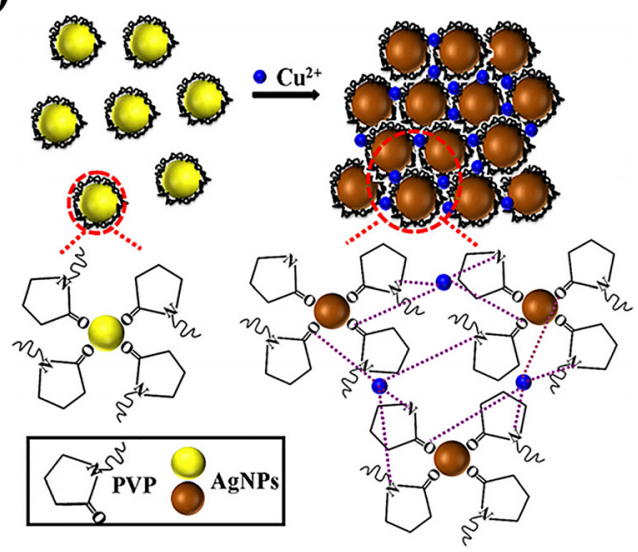

(d)

(a) Traditional model

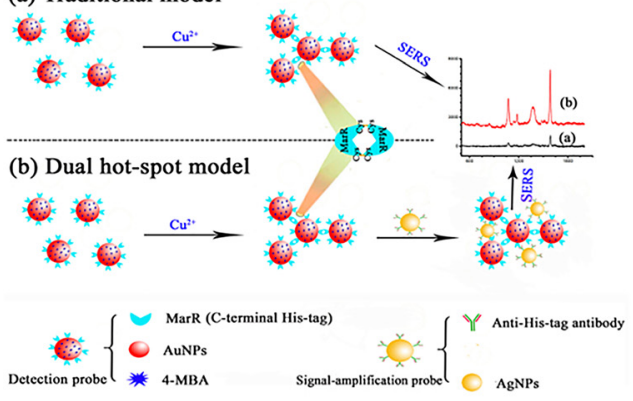

(e)
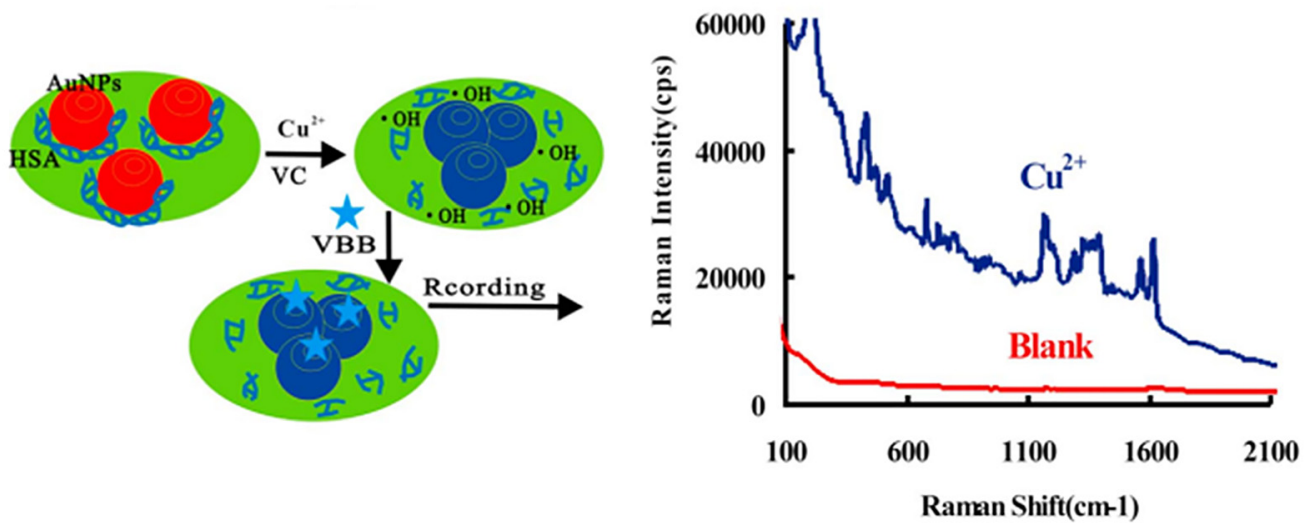

Figure 4: SERS-based $\mathrm{Cu}^{2+}$ ions detection.

(a) $\mathrm{Cu}^{2+}$ ions bond with cysteine [72]. (b) $\mathrm{Cu}^{2+}$ ions linked with PVP [77]. (c) A dual hot spot signal amplification strategy based on antigen-antibody reaction [78]. (d) $\mathrm{Cu}^{2+}$ ions oxidized L-cysteine to cystine [79]. (e) Taking place catalytic reaction and generating strongly oxidizing $\bullet \mathrm{OH}$ in the presence of $\mathrm{Cu}^{2+}$ ions [82].

which not only promoted AgNPs' aggregation but also changed the electronic structure of PVP, thus significantly enhancing the Raman signal. The LOD of this method reached $3 \mathrm{nM}$ with a linear range from 0.01 to $2 \mu \mathrm{M}$.

Determination of copper ions with other strategies. Wang et al. created a dual signal amplification strategy based on antigen-antibody reaction to recognize copper ions (Figure 4c) [78]. Specifically, they started with decorating the multiple antibiotic resistance regulator (MarR) that worked as bridging molecules and 4-MBA served as a Raman reporter on the surface of AuNPs, and then $\mathrm{Cu}^{2+}$ ions generated disulfide bonds between the two MarR dimers by 
Table 3: The assays of detection of copper ions based on the SERS method.

\begin{tabular}{|c|c|c|c|c|c|}
\hline SERS substrate & Raman reporter & Range & LOD & Comments & Ref. \\
\hline AuNPs & $\mathrm{MBIm}$ & $15-40 \mu \mathrm{M}$ & $15 \mu \mathrm{M}$ & Simple, rapid but low sensitivity & [71] \\
\hline GNS & Cysteine & - & $10 \mu \mathrm{M}$ & Simple but low sensitivity & [72] \\
\hline AuNR-PCL ${ }^{b}$ & TMT & $10^{-6}-10^{-4} \mathrm{M}$ & - & Low sensitivity and not novel & [73] \\
\hline AgNPs & PVP & $0.01-2 \mu \mathrm{M}$ & $3 \mathrm{nM}$ & Simple, rapid but low reproducibility & [77] \\
\hline AuNP-AgNP heterodimers & 4-MBA & $0.5-1000 \mathrm{nM}$ & $0.18 \mathrm{nM}$ & Rapid, sensitive but complicated & [78] \\
\hline L-Cys/IP6@AgNPs & R6G & $10^{-5}-10^{-10} M$ & $10 \mathrm{pM}$ & Sensitive, wide linear range but low reproducibility & [79] \\
\hline AuNP-SiO ${ }_{2}$ sol & VBB & $0.025-25 \mu \mathrm{M}$ & $0.008 \mu \mathrm{M}$ & Sensitive, selective but low reproducibility & [82] \\
\hline
\end{tabular}

${ }^{\mathrm{a}}$ 2-mercaptobenzimidazole (MBIm); ${ }^{\mathrm{b}}$ polycaprolactone (PCL).

oxidizing cysteine residues, which induced the formation of the MarR tetramers, leading to the aggregation of AuNPs and the reinforcement of the SERS signal of 4-MBA. In the meantime, another substrate, AgNPs capped with anti-Histag antibodies combined with MarR (C-terminal His tag) to constitute dual hot spots and the reticulation of AuNP-AgNP heterodimers. The dramatic signal enhancement allowed the detection limit to reach $0.18 \mathrm{nM}$ with a linear response in the range of 0.5-1000 nM. Yang's team also proposed an ingenious method to detect copper ions by oxidizing cysteine [79]. The possible detection mechanism is described in Figure 4d. First of all, inositol hexaphosphate (IP6) acted as a protective coating on the AgNPs' surface. Subsequently, L-cysteine and R6G were adorned on the IP6@Ag. R6G produced a strong signal due to the aggregation of nanoparticles via the carboxyl group of L-cysteine. However, in the presence of $\mathrm{Cu}^{2+}$ ions, L-cysteine and IP6 could capture and accumulate copper ions. When a certain concentration was reached, copper ions oxidized L-cysteine to cystine, thus increasing the distance between nanoparticles and reducing hot spots, which resulted in weakening the SERS signal of R6G. The LOD of this turn-off mode reached $10 \mathrm{pM}$ with an excellent linear range from $10^{-5}$ to $10^{-10} \mathrm{M}$. In addition, copper ions also play a significant role in the application of biocatalysis [80, 81]. As a biological macromolecule, human serum albumin (HSA) can form a stable complex with AuNPs via gravitational charge in the presence of a high concentration of $\mathrm{NaCl}$. Under the condition of copper ion and ascorbic acid $\mathrm{H}_{2} \mathrm{~A}$, the two particles underwent a catalytic reaction and generated strongly oxidizing $\bullet \mathrm{OH}$, which made HSA hydrolyze into peptide and amino acid, and desorb from the gold surface. At the same time, the exposed gold surface was reaggregated under the influence of $\mathrm{NaCl}$, and the Victoria blue B (VBB) signal used as the SERS reporter was improved. The SERS sensor platform displayed a preferable linear range from 0.025 to $25 \mu \mathrm{M}$ with a detection limit of $0.008 \mu \mathrm{M}$ (Figure 4e) [82]. The assays of detection of $\mathrm{Cu}^{2+}$ based on SERS are presented in Table 3.

\subsection{Detection of arsenic(III) and arsenic(V)}

As one of the most toxic substances in the natural environment, arsenic contamination in water has become a global epidemic that poses a great threat to human health $[83,84]$. Long-term arsenic ingestion has been shown to increase the risk of various kinds of cancers, skin diseases, cardiovascular disease, and developmental and reproductive problems [85-87].

As two forms of inorganic arsenic, arsenic(III) mainly exists in the form of arsenite, while arsenic $(\mathrm{V})$, prevails in oxygen-containing water and mainly exists in the form of arsenate $[88,89]$. Under the current situation, the rapid and efficient detection of arsenic has motivated researchers to keep exploring. Arsenic can be directly detected via the characteristic vibration of the As-O band [31]. For the $v_{1}$ $\left(\mathrm{A}_{1}\right)$ symmetric and $v_{2}\left(\mathrm{~A}_{1}\right)$ and $v_{5}(\mathrm{E})$ stretching modes of the As-O band, there are two characteristic peaks of pentavalent arsenic at around $780-812 \mathrm{~cm}^{-1}$ and $420 \mathrm{~cm}^{-1}$, and trivalent arsenic at approximately $720-750 \mathrm{~cm}^{-1}$ and $439 \mathrm{~cm}^{-1}$, respectively [90]. Taking advantage of this property, various SERS substrates were applied to determine trace arsenic. In addition, arsenic ions can also coordinate with some specific atoms or aptamers to change the aggregation of nanoparticles and further alter the SERS signal of Raman reporters.

Direct detection of arsenic by various SERS substrates: With the aim of determination of trace arsenate and arsenite, Yang et al. made use of the Langmuir-Blodgett (LB) self-assembly strategy to synthesize Ag nanoarrays with three shapes, namely, cubes, cuboctahedra, and octahedra (Figure 5a) [91]. Among the three structures, octahedral particles exhibited the most prominent enhancement factor $\left(10^{7}-10^{8}\right)$ and the most outstanding sensitivity, which was able to detect arsenate at $1 \mathrm{ppb}$. In 2011, multilayer Ag nanofilms with higher density and more uniform distribution which allowed more $\mathrm{As}(\mathrm{V})$ to be adsorbed directly onto the silver surface were fabricated for 
the analysis of pentavalent arsenic [92]. The LOD was as low as $5 \mathrm{ppb}$. Two years later, a fast, low-budget, and scalable oil-water interfacial self-assembly process for preparing oriented Ag nanowire (AgNW) films on a solid base was reported [93]. Compared with the conventional LB process, this technique had a simpler operation and did not require pretreatment of the substrate surface. The SERS substrate with satisfactory uniformity and repeatability displayed the excellent capacity to recognize As(V) with a LOD of $5 \mathrm{ppb}$. In 2014, Jing et al. presented an $\mathrm{Fe}_{3} \mathrm{O}_{4} @ \mathrm{Ag}$ core-shell magnetic nanostructure with the advantages of rapid enrichment and separation to determine $\mathrm{As}(\mathrm{III})$ and $\mathrm{As}(\mathrm{V})$, and the time for the whole process of actual detection was only $2 \mathrm{~min}$ [94]. A benign linear correlation was exhibited between the SERS peak at $780 \mathrm{~cm}^{-1}$ and arsenic concentration from 0 to $1000 \mathrm{ppb}$. A low LOD of $10 \mathrm{ppb}$ can be obtained. With the rapid development of a three-dimensional (3D) SERS substrate, $\mathrm{Xu}$ et al. first developed a 3D SERS substrate consisting of $\mathrm{Ag} / \mathrm{AuNRs}$ plated on electrospun polycaprolactide (PCL) fibers for in situ quantitative analysis and measurement of $\mathrm{As}(\mathrm{V})$ [95]. The 3D SERS substrate showed higher sensitivity and reproducibility than one- or two-dimensional bases and provided appropriate surface chemical detection for $p$-arsanilic acid combined with DFT. The designed 3D structure revealed a LOD of $4 \mathrm{ppb}$ in water and $8 \mathrm{ppb}$ in ionic coexistence solution.

Analysis of arsenic by coordinating with specific structures: It is well known that As-O has a Raman vibration peak, so $\mathrm{As}^{3+}$ ions can be utilized to form chemical bonds with $\mathrm{O}$ atoms to make nanoparticles aggregate. The avenue was first put forward by Wang's group (Figure $5 b$ ) [96]. They modified glutathione (GSH) and 4-MPY on the AgNPs' surface, in which 4-MPY was employed as a Raman reporter. When arsenic ions were added, the carboxyl group of GSH could be connected with $\mathrm{As}^{3+}$ ions via three As-O bonds, which promoted the aggregation of AgNPs, producing more hot spots and improved the SERS signal of 4-MPY. Under optimal reaction conditions, the assay had an excellent linear relationship from 4 to $300 \mathrm{ppb}$, and the LOD was estimated to be $0.76 \mathrm{ppb}$. Based on the same principle and combined with zigzag microfluidic chip technology, Chen et al. proposed a strategy for detecting trace $\mathrm{As}^{3+}$ ions, with a detection limit down to $0.67 \mathrm{ppb}$ [97]. Aptamers are nucleotide sequences that can specifically bind to target molecules which are widely applied in biosensors [98]. In addition to mercury and silver ions, which can be complexed to form $\mathrm{T}-\mathrm{Hg}^{2+}-\mathrm{T}$ and $\mathrm{C}-\mathrm{Ag}^{+}-\mathrm{C}$ structures, arsenic ions also selectively bind to aptamers. For instance, Jiang

(a)
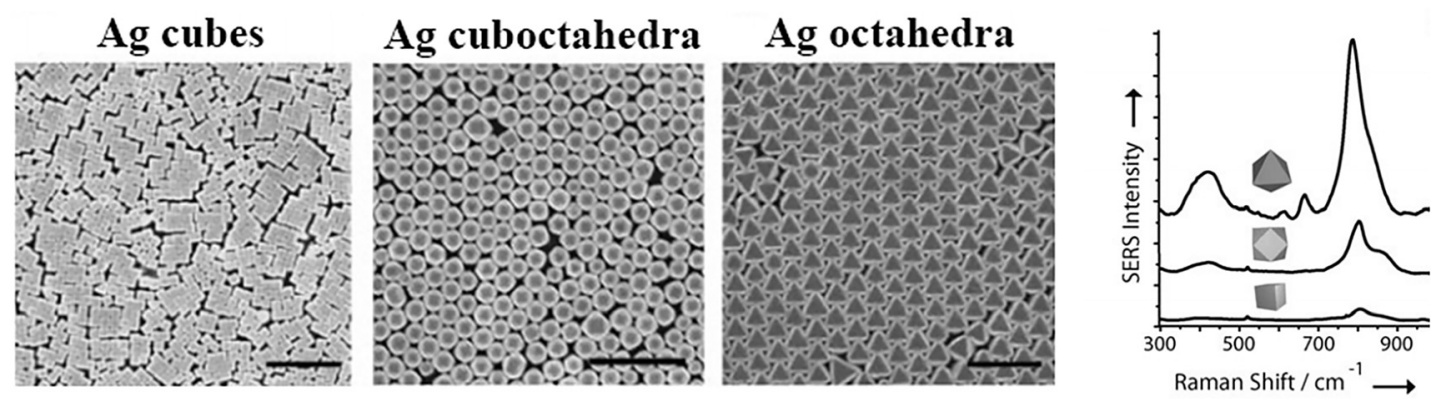

(b)

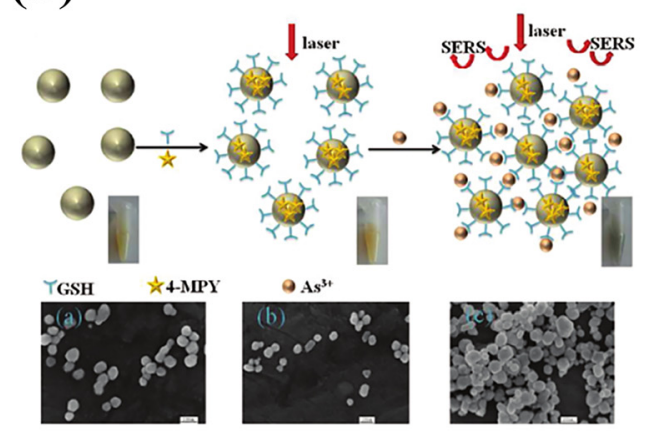

(c)

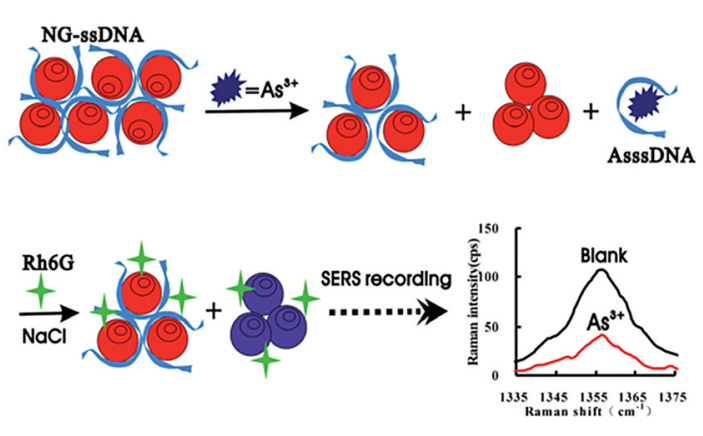

Figure 5: Representative strategies for efficient detection of $\mathrm{As}(\mathrm{III})$ or $\mathrm{As}(\mathrm{V})$.

(a) Direct detection of arsenate and arsenite based on the characteristic peaks at 800 and $425 \mathrm{~cm}^{-1}$ [91]. (b) Aggregation induced by combining with GSH [96]. (c) $\mathrm{As}^{3+}$ ions are specifically complexed with aptamer [99]. 
Table 4: Strategies for determination of $\mathrm{As}^{3+}$ and $\mathrm{As}^{5+}$ ions.

\begin{tabular}{lllllll}
\hline SERS substrate & Raman repoters & Ion type & Range & LOD & Comments \\
\hline AgNAs $^{\mathrm{a}}$ & - & $\mathrm{As}(\mathrm{V})$ & $1-180 \mathrm{ppb}$ & $1 \mathrm{ppb}$ & Reproducible, portable but complicated \\
$\mathrm{Ag}$ nanofilms & - & $\mathrm{As}(\mathrm{V})$ & $0-250 \mathrm{ppb}$ & $5 \mathrm{ppb}$ & Uniform, reproducible but not novel \\
$\mathrm{AgNW}$ & - & $\mathrm{As}(\mathrm{V})$ & $0-500 \mathrm{ppb}$ & $5 \mathrm{ppb}$ & Low-cost, simple but low reproducibility \\
$\mathrm{Fe}_{3} \mathrm{O}_{4} @ \mathrm{AgNPs}$ & - & $\mathrm{As}(\mathrm{III}), \mathrm{As}(\mathrm{V})$ & $0-1000 \mathrm{ppb}$ & $10 \mathrm{ppb}$ & Rapid, portable but low reproducibility \\
$\mathrm{Ag} / \mathrm{AuNRs}-\mathrm{PCL}$ & - & $\mathrm{As}(\mathrm{V})$ & $5 \times 10^{-8}-10^{-5} \mathrm{M}$ & $4 \mathrm{ppb}$ & Versatile, uniform but complicated \\
& & & $(1.32 \mathrm{ppb}-2.63 \mathrm{ppm})$ & & \\
$\mathrm{Cu}_{2} \mathrm{O} / \mathrm{AgNPs}$ & - & $\mathrm{As}(\mathrm{III}), \mathrm{As}(\mathrm{V})$ & $1-20 \mathrm{ppb}$ & $5.61 \mathrm{ppt}$ & Sensitive, reproducible, and stable \\
$\mathrm{AgNPs}$ & $4-\mathrm{MPY}$ & $\mathrm{As}(\mathrm{III})$ & $4-300 \mathrm{ppb}$ & $0.76 \mathrm{ppb}$ & Sensitive, selective but low reproducibility \\
$\mathrm{AgNPs}$ & $4-\mathrm{MPY}$ & $\mathrm{As}(\mathrm{IIII})$ & $3-200 \mathrm{ppb}$ & $0.67 \mathrm{ppb}$ & Sensitive but not novel \\
AuNPs & $\mathrm{R} 6 \mathrm{G}$ & $\mathrm{As}(\mathrm{III})$ & $0.288-23.04 \mathrm{ppb}$ & $0.1 \mathrm{ppb}$ & Lable-free, sensitive but low reproducibility \\
Au@AgNPs & $4-\mathrm{MPY}$ & $\mathrm{As}(\mathrm{III})$ & $0-100 \mathrm{ppb}$ & $59 \mathrm{ppt}$ & Sensitive, selective but low reproducibility \\
\hline
\end{tabular}

${ }^{\mathrm{a}} \mathrm{Ag}$ nanoarrays (AgNAs).

et al. constructed a SERS platform for the quantitative determination of $\mathrm{As}^{3+}$ ions in an aptamer-nanoparticle (Figure 5c) [99]. They first decorated ssDNA and R6G on the surface of AuNPs. Under the influence of $\mathrm{NaCl}$, AuNPs approached each other and formed stable red aggregations which promoted the generation of a strong SERS signal of R6G at $1358 \mathrm{~cm}^{-1}$. Once arsenic ions were added, they combined with ssDNA to formulate a steady complex of AsssDNA, accompanied by releasing AuNPs which further converged to AuNP aggregates, finally resulting in a weakened SERS signal of R6G. The turn-off mode showed linearity with the concentration of $\mathrm{As}^{3+}$ ions from 0.288 to $23.04 \mathrm{ppb}$, with a LOD of $0.1 \mathrm{ppb}$. The turn-on mode was also utilized to detect trivalent arsenic ions according to a similar mechanism [100]. Table 4 compares different strategies for the determination of $\mathrm{As}^{3+}$ and $\mathrm{As}^{5+}$ ions.

\subsection{Detection of zinc and cadmium ions}

As a necessary trace element, zinc plays an indispensable role in gene expression, endocrine, cell metabolism, reproductive inheritance, DNA recognition, human growth and development, and other physiological processes [102, 103]. Zinc deficiency can bring about unhealthy symptoms such as loss of appetite, growth retardation, mental retardation, decreased immune function, epilepsy, prostate cancer, and impaired reproductive function [104, 105]. High levels of zinc in cells promote apoptosis, which leads to various diseases such as Alzheimer's disease [106]. Cadmium is also one of the most toxic heavy metal ions; it has been considered as a potential threat to human health due to its difficulty in degradation and enrichment in organisms. Cadmium poisoning can produce serious kidney injury, central nervous system damage, stomach pain, cancer, and so on [107]. The determination of zinc ions and cadmium ions was mainly based on their coordination with specific atoms, in which zinc ions can bond with nitrogen and oxygen atoms, while cadmium mainly forms complexes with oxygen atoms. Because of the similarity of their electronic structures, zinc and cadmium will interfere with each other in the actual detection application [108]. Therefore, it is necessary to exploit an ultrasensitive and selective SERS sensor to analyze trace zinc ions and cadmium ions.

Determination of zinc ions by bonding with certain atoms: Zinc ion is not as toxic as other heavy metal ions, so studies have relatively few tests for zinc ions. In 2011, Szabó et al. successfully made use of the SERS approach to detect the zinc ions in contaminated soil in an industrial region and obtained consistent results with the Romanian Environmental Protection Agency in this area [109]. In their work, a common azo reporter, 4-(2-pyridylazo)resorcinol (PAR), can be coordinated into a $\mathrm{Zn}(\mathrm{PAR})_{2}$ complex with zinc ion in a 2:1 manner through the nitrogen atom on the pyridine ring, azo nitrogen atoms, and phenolic hydroxyl group according to the DFT calculation. It was believed that the soil contained zinc ions through observing the SERS signal of the compound. However, the copper ions in this method produced certain interference because it could also form a complex with PAR. 4-MPY was reported to be used to detect zinc ions in 2016 [110]. When zinc ions complexed with 4-MPY, two new peaks at $1027 \mathrm{~cm}^{-1}$ and $1594 \mathrm{~cm}^{-1}$ appeared due to the interaction between them, which affected the ring breathing and $\mathrm{C}-\mathrm{C}$ stretching vibration of the molecular complex. Nevertheless, the antiinterference ability and sensitivity of this strategy need to be further improved. Two years later, a novel ultrasensitive and highly selective SERS-based platform was put forward by Li's group (Figure 6a) [111]. They choose $N, N^{\prime}$-bis (2-hydroxybenzylidene)-4-aminophenyl disulfide (HBA) as 
a metal chelator. In their design, HBA connected with AgNPs through Ag-S bonding following breakage of the disulfide bond of HBA. The two separate half-HBA molecules were then employed as Raman reporters and coordinated with $\mathrm{Zn}^{2+}$ ions strongly, which resulted in a shift of the characteristic peak at $1563 \mathrm{~cm}^{-1}$ of half-HBA due to the change of electron structure and redistribution of charge. What was mentioned above can be used as a quantitative basis for the detection of zinc ions. The proposed method exhibited excellent linearity from $10^{-15}$ to $10^{-6} \mathrm{M}$ and an unprecedentedly low detection limit of $10^{-14} \mathrm{M}$, and was applied to the determination of intracellular zinc ion concentration. In addition to the aforementioned ligands, di2-picolylamine (DPA) is considered to be one of the most common ligands capable of complexing with $\mathrm{Zn}^{2+}$ ions and has been widely used in fluorescence analysis [112, 113]. Inspired by previous work, Lee and coworkers synthesized a DPA derivative called di-2-picolylamine-triarylmethine (DPA-TMT), which is able to sensitively monitor $\mathrm{Zn}^{2+}$ ions in a water environment (Figure 6c) [114]. In their model, DPA-TMT was adsorbed on the AuNPs' surface via nitrogen atoms. When zinc ions were added to the system, two DPA-TMT molecules specifically bond with $\mathrm{Zn}^{2+}$ ions, which shortened the distance between AuNPs, thereby increasing the SERS signal of DPA-TMT and the LOD was around $50 \mu \mathrm{M}$. What is more, the proposed DPA-TAM-AuNP self-assembly system could be successfully applied to the determination of the intracellular $\mathrm{Zn}^{2+}$ ions concentration in both human cervical carcinoma HeLa cells and daphnia via dark-field microscopy-equipped Raman cellular imaging. Because zinc ion concentration is strongly associated with prostate cancer, Teng et al. proposed liquid-liquid self-assembled Au nanoarrays (AuNAs) modified with a 2-carboxy-2'-hydroxy-5'-sulfoformazylbenzene (Zincon) strategy to measure zinc ion concentration in prostate fluid (Figure 6b) [115]. Under the optimal reaction conditions, after the $\mathrm{Zn}^{2+}$ ions bond to the Zincon, a new peak would be generated at $532 \mathrm{~cm}^{-1}$ attributed to the wagging vibration of $\mathrm{Zn}-\mathrm{N}$ and the ring deformation, which could serve as the foundation of quantitative detection. As the concentration of zinc ions increased from 0.5 to $200 \mu \mathrm{M}$, the Raman intensity at $532 \mathrm{~cm}^{-1}$ gradually enhanced. A satisfactory linear range from 0.5 to $10 \mu \mathrm{M}$ and LOD of $0.1 \mu \mathrm{M}$ were obtained.

Detection of cadmium ions by bonding with certain structures: Because cadmium ions can specifically bind to oxygen atoms, many researchers were committed to synthesizing Raman reporters that can coordinate with cadmium ions or modifying multifunctional Raman reporters on the surface of metal nanoparticles. For instance, Yin et al. designed a novel class of turn-on mode SERS sensors to determine $\mathrm{Cd}^{2+}$ ions by making use of the interparticle plasmonic coupling produced by $\mathrm{Cd}^{2+}$ ions combined with 2(4-(2-hydroxyethylamino)-4-oxobutanamido)ethyl methacrylate (HEBAMA) (Figure 6d) [116]. They first functionalized the surface of $41 \mathrm{~nm}$ gold nanoparticles with Raman tag 2-(4(bis(4-(diethylamino)phenyl) (hydroxy)-methyl)phenoxy) ethyl-5-(1,2-dithiolan-3-yl)pentanoate (BGLA), followed by the modification of methoxypoly(ethylene glycol)thiol (PEG-SH), which served as a colloid stabilizer and a surfaceinitiated atom transfer radical polymerization (SI-ATRP) initiator, 2,2'-dithiobis[1-(2-bromo-2-methylpropionyloxy)] ethane which had two effects: preventing nonspecific aggregation of AuNPs and distinguishing $\mathrm{Cd}^{2+}$ ions via a specific metal-ligand reaction. Once cadmium ions were added, they interacted with HEBAMA in the cases of consecutive ligand exchange and surface-initiated ATRP reactions, resulting in the self-aggregation of AuNPs and an increase in the intensity of Raman reporter of BGLA upon the influence of more "hot spots." The protocol effectively distinguished $\mathrm{Zn}^{2+}$ ions from $\mathrm{Cd}^{2+}$ ions, and the detection limit was down to $1.0 \mu \mathrm{M}$. Although huge progress has been made, the synthesis process of this method was very complicated. As illustrated in Figure 6e, a simpler experimental scheme was performed by Dasary and coworkers [117]. Alizarin, as a Raman reporter, was immobilized on the surface of plasmonic AuNPs. Afterward, 3-mercaptopropionic acid (MPA) and 2,6-pyridinedicarboxylic acid (PDCA) which provided active sites for coordination with $\mathrm{Cd}^{2+}$ ions were also functionalized with AuNPs. Upon addition of $\mathrm{Cd}^{2+}$ ions, the Alizarin-MPA-PDCA system strongly bonds with $\mathrm{Cd}^{2+}$ ions through nitrogen and oxygen atoms, facilitating the aggregation of AuNPs and enhancing the Raman signal of Alizarin simultaneously. The novel SERS assay greatly saved time and improved sensitivity so that the LOD was 10 ppt. In 2019, Du et al. created an approach for the simultaneous detection of cadmium ions and polycyclic aromatic hydrocarbons (PAHs), according to which dopamine was oxidized to various products through a classic Raper-Mason reaction mechanism (Figure 6f) [118]. Dopamine (DA), which acted as a reducing agent during the synthesis of gold nanoparticles, was finally oxidized to dopamine quinone (DQ), 5,6-dihydroxyindole, and polydopamine (PDA). Substances with different structures adsorbed on the AuNPs surface could synthesize AuNPs with different sizes and had diverse functions. Among them, DQ displayed an excellent capacity for coordinating with $\mathrm{Cd}^{2+}$ ions via quinone functional groups, while PDA had the ability to lock PAHs in SERS hot spots as a reaction vessel, which both exhibited a good linear relationship toward concentration of $\mathrm{Cd}^{2+}$ ions and PAHs with a low detection limit. In addition to detecting $\mathrm{Cd}^{2+}$ ions by coordination mode, it can 
(a)

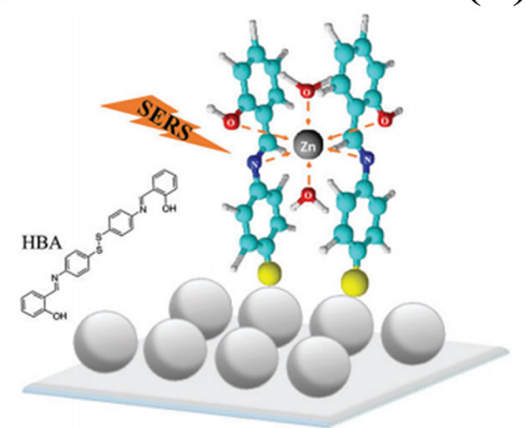

(c)

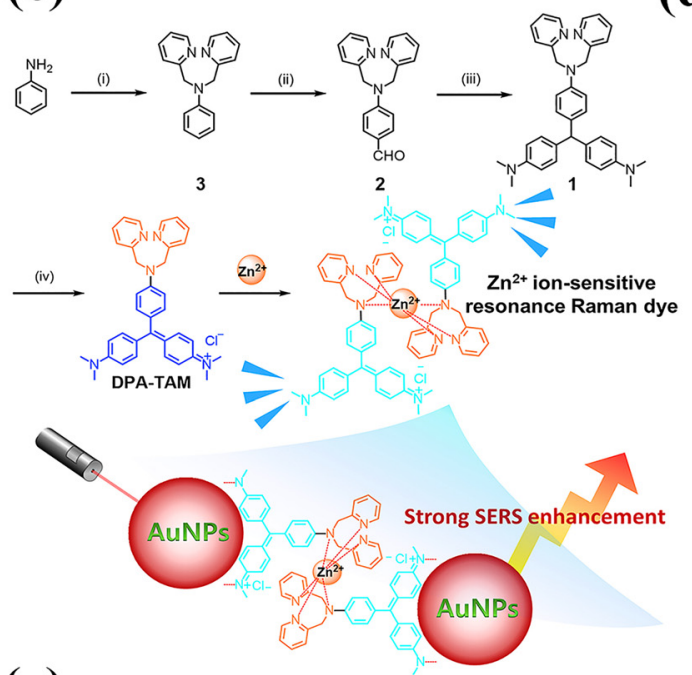

(e)

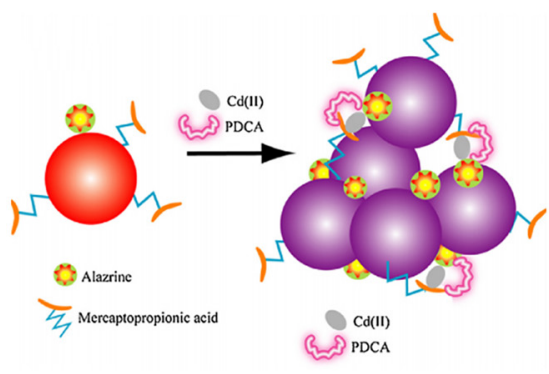

(f) (b)

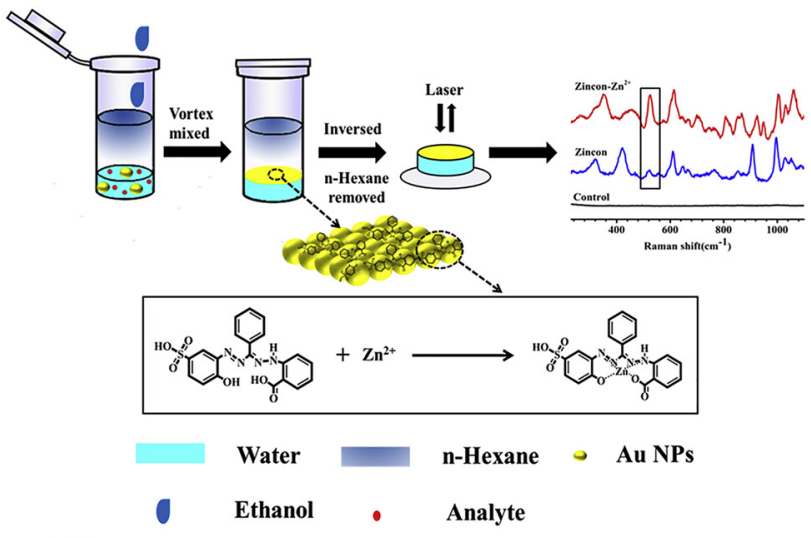

(d)

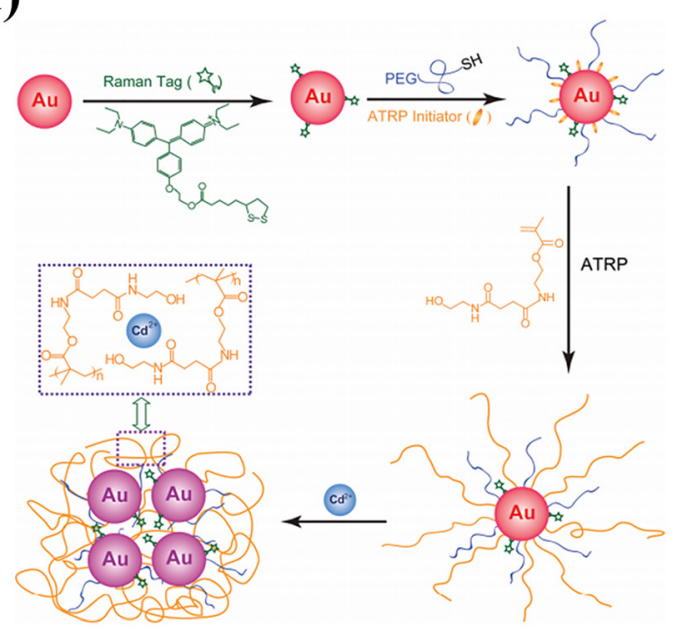

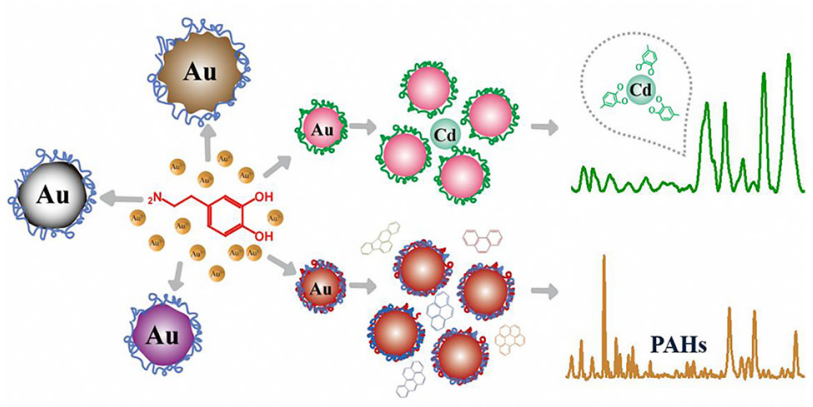

Figure 6: Different SERS sensors for detection of $\mathrm{Zn}^{2+}$ and $\mathrm{Cd}^{2+}$ ions.

(a) $\mathrm{Zn}^{2+}$ ions coordinated with HBA on Ag nanofilm [111]. (b) $\mathrm{Zn}^{2+}$ ions bond to the Zincon on the surface of the liquid-liquid self-assembled AuNAs [115]. (c) DPA-TAM-AuNP self-assembly system to detect $\mathrm{Zn}^{2+}$ ions [114]. (d) $\mathrm{Cd}^{2+}$ ions combined with HEBAMA [116]. (e) Initial alizarin adsorption, and subsequent MPA-PDCA conjugation on the surface of AuNPs [117]. (f) Simultaneous detection of $\mathrm{Cd}^{2+}$ ions and PAHs according to the oxidation of dopamine through a classic Raper-Mason reaction mechanism [118].

also be recognized by colorimetry based on SERS-active silica-gold nanocomposite $\left(\mathrm{SiO}_{2} @\right.$ AuNCs) material [119]. When $0.1 \mathrm{ppm}$ of cadmium ions were added to the colloid, the color of the $\mathrm{SiO}_{2} @ A u N C s$ sol quickly became gray, which could be observed by the naked eye and UV-vis spectrum without interference from other metal ions. Although traditional colorimetry has the advantages of convenience and speed, its sensitivity needs to improve. The methods of detection of $\mathrm{Zn}^{2+}$ and $\mathrm{Cd}^{2+}$ ions are summarized in Table 5. 
Table 5: The methods of detection of $\mathrm{Zn}^{2+}$ and $\mathrm{Cd}^{2+}$ ions based on the SERS technique.

\begin{tabular}{lllllll}
\hline SERS substrate & Raman reporter & Ions & Linear range & LOD & Comments & Ref. \\
\hline AgNPs & PAR & $\mathrm{Zn}^{2+}$ & - & - & Low sensitive and selectivity & [109] \\
AgNP-Si & 4-MPY & $\mathrm{Zn}^{2+}$ & $0.1-10 \mathrm{mM}$ & - & Uniform but low selectivity & {$[110]$} \\
Ag nanofilms & $\mathrm{HBA}$ & $\mathrm{Zn}^{2+}$ & $10^{-15}-10^{-6} \mathrm{M}$ & $10^{-14} \mathrm{M}$ & Sensitive, selective but low reproducibility & {$[111]$} \\
AuNPs & DPA-TMT & $\mathrm{Zn}^{2+}$ & $0-100 \mu \mathrm{M}$ & $50 \mu \mathrm{M}$ & Selective but low sensitive & {$[114]$} \\
AuNAs & Zincon & $\mathrm{Zn}^{2+}$ & $0.5-10 \mu \mathrm{M}$ & $0.1 \mu \mathrm{M}$ & Uniform, selective but low sensitive \\
AuNPs & BGLA & $\mathrm{Cd}^{2+}$ & - & $1.0 \mu \mathrm{M}$ & Selective but low sensitive, complicated & {$[115]$} \\
AuNPs & Alizarin & $\mathrm{Cd}^{2+}$ & - & $89 \mathrm{pM}$ & Sensitive, selective but low reproducibility & {$[117]$} \\
AuNPs & DA & $\mathrm{Cd}^{2+}$ & $10^{-4}-10^{-8} \mathrm{M}$ & $10^{-8} \mathrm{M}$ & Versatile, selective but low reproducibility & {$[118]$} \\
$\mathrm{SiO}_{2} @ A u N C s$ & $\mathrm{CV}$ & $\mathrm{Cd}^{2+}$ & $0.1-2 \mathrm{ppm}(0.89-17.8 \mu \mathrm{M})$ & $89 \mu \mathrm{M}$ & Low sensitive, selectivity and reproducibility & {$[119]$} \\
\hline
\end{tabular}

\subsection{Detection of lead ions}

Lead is widely applied in the fields of batteries, smelting production, and so on [120], but with the development of industry, lead pollution has become more serious. Exposure to even a very low concentration of lead ions can also cause numerous dangerous symptoms such as kidney damage, anemia, memory loss, mental retardation, and reproductive system impairment [121, 122]. The above contents undoubtedly illustrate the importance of trace detection and pollution monitoring for lead ions. There are two main methods for detecting lead ions: one is to make use of $\mathrm{Pb}^{2+}$-dependent DNAzyme as a cofactor that has high catalytic activity for lead ions, and the Raman reporter can approach or stay away from the noble metal substrate by cleaving the DNA. The other is to modify specific functional groups on the surface of metal nanoparticles and induce the self-aggregation of nanoparticles and generate a stronger SERS signal through the coordination of lead ions with some groups or atoms.

Determination of lead ion via $\mathrm{Pb}^{2+}$-dependent DNAzyme: DNAzyme is a class of nucleic acids that has RNA nuclease activity and the capability of decomposing the ribonucleotide. Most DNAzymes rely on neutral molecules or metal ions as cofactors [123]. The $\mathrm{Pb}^{2+}$-dependent DNAzyme as a cofactor has high catalytic activity for lead ions. In recent years, various SERS sensors for $\mathrm{Pb}^{2+}$ based on $\mathrm{Pb}^{2+}$-dependent DNAzyme have been reported [124, 125]. For example, Wang et al. proposed a sensitive and specific SERS-DNAzyme biosensor in 2011 (Figure 7a) [126]. First, the DNAzyme was fixed on a gold-plated surface by the strong $\mathrm{Au}-\mathrm{S}$ bond, in which the surface was sealed by a small molecule of 6-mercaptohexane. Then, the cleavage substrate was hybridized specifically with the DNAzyme. At the other end of the cleavage substrate, a conjugate can be formed via hybridizing with AuNPs functionalized with mercaptobenzoic acid (MBA). When $\mathrm{Pb}^{2+}$ ions bond to the DNAzyme, a certain amount of AuNPs conjugate was dissociated from the gold surface, resulting in a weakened Raman signal. The detection range is from $20 \mathrm{nM}$ to $1 \mu \mathrm{M}$ with a minimum detection concentration of $20 \mathrm{nM}$. Similarly, He's group designed a polyadenine-assisted SERS silicon chip decorated with core $(\mathrm{Ag})$-satellite $(\mathrm{Au})$ nanoparticles for high-performance $\mathrm{Pb}^{2+}$ ions' determination (Figure 7b) [127]. They first constructed a dsDNA on the surface of the nanoparticles composed of DNAzyme strand (Cy5-17E-SH) and its complementary strand (17DS). Because of the rigid structure of dsDNA, Cy5, as a Raman label, stays away from the nanoparticles and generates a feeble SERS signal. When the complexation between $\mathrm{Pb}^{2+}$ ions and DNAzyme was activated, the substrate strand was cleaved into two parts, and Cy5 was close to the metal nanoparticles, which induced a significant enhancement of the SERS signal. There is an obvious dependent relationship between the change of intensity and the logarithmic concentration of $\mathrm{Pb}^{2+}$ ions from $10 \mathrm{pM}$ to $1 \mu \mathrm{M}$ with a low LOD of $8.9 \mathrm{pM}$. Recently, Xu et al. have successfully implemented the highly sensitive detection of lead ions in human serum using DNAzyme-modified $\mathrm{Fe}_{3} \mathrm{O}_{4} @ \mathrm{Au} @ \mathrm{Ag}$ nanoparticles $\left(\mathrm{Fe}_{3} \mathrm{O}_{4} @ \mathrm{Au} @ A g N P s\right)$ according to a similar sensing principle (Figure 7c) [128]. The detection limit was down to $5 \mathrm{pM}$. The $\mathrm{Pb}^{2+}$-dependent DNAzyme-based SERS sensors exhibited some unique advantages such as high selectivity and sensitivity compared with traditional metal sensors, which has great development potential in future biological and chemical detection.

Detection of lead ions via binding with specific groups: Like mercury ion, copper ion, arsenic ion, zinc ion, and cadmium ion, lead ions can also bind to certain substances such as citrate [129], glucose [130], L-cysteine [131], and cucurbit[7]uril (CB[7]) [132], which induce the aggregation of metal nanoparticles or keep the Raman reporter away from the metal nanoparticles. For instance, Frost et al. demonstrated a citrate-modified AuNPs SERS sensor to analyze lead ions relying on the coordination interaction between the lead ions and the carboxylate and 
(a)

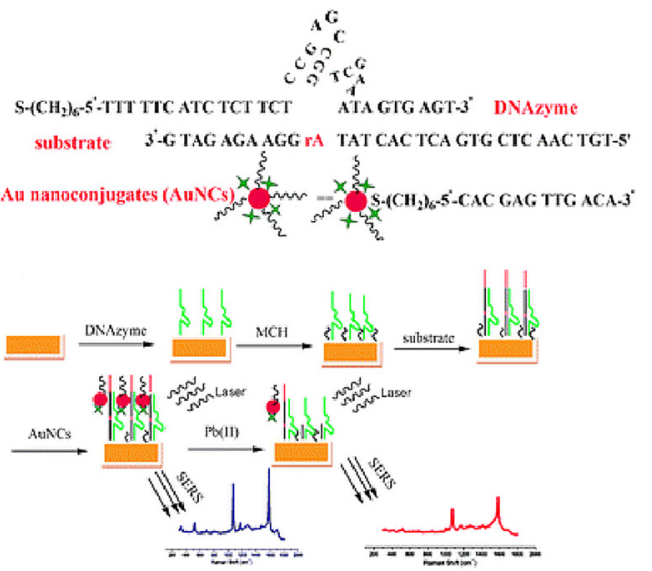

(b)

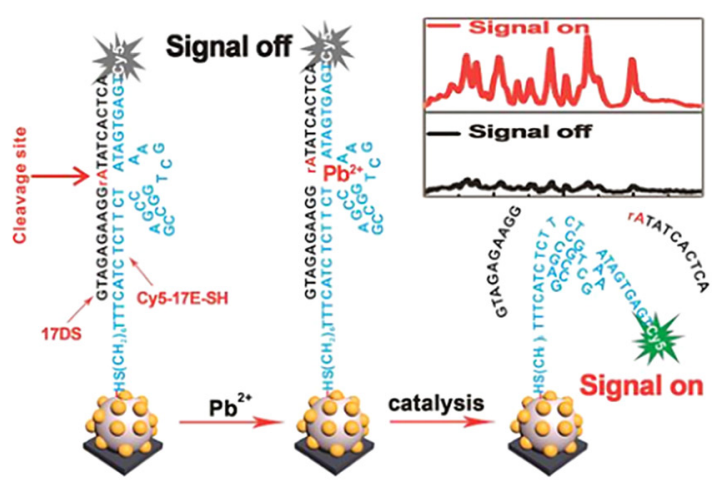

(c)

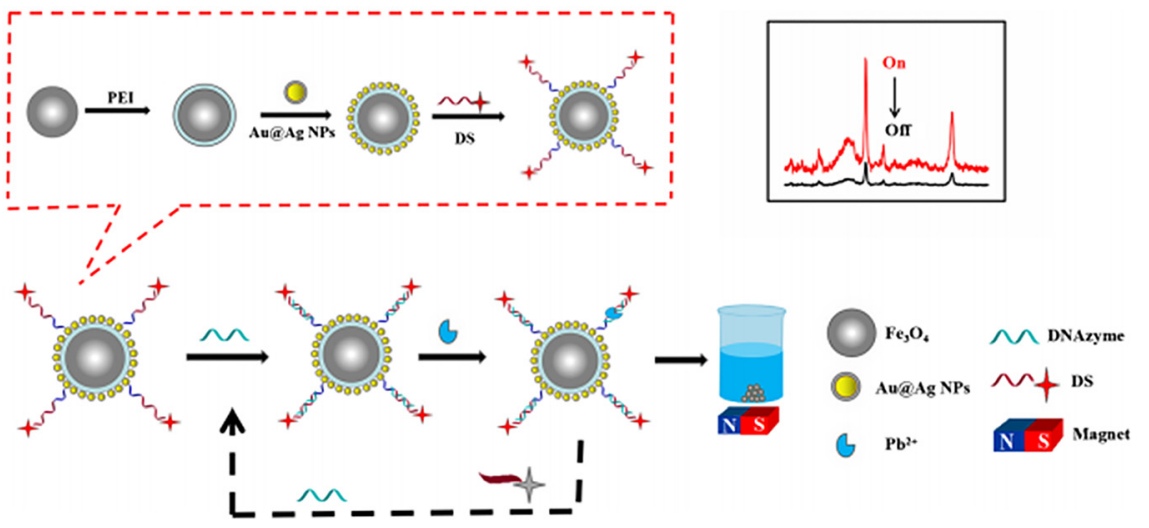

Figure 7: Determination of $\mathrm{Pb}^{2+}$ ions via $\mathrm{Pb}^{2+}$-dependent DNAzyme.

(a) $\mathrm{Pb}^{2+}$ ions bond specifically to the DNAzyme on the gold-plated surface [126]. (b) Cy5 was close to the metal nanoparticles due to the activation of complexation between $\mathrm{Pb}^{2+}$ ions and DNAzyme [127]. (c) Highly sensitive detection of $\mathrm{Pb}^{2+}$ ions using DNAzyme-modified $\mathrm{Fe}_{3} \mathrm{O}_{4} @ \mathrm{Au} @ A g N P s[128]$.

hydroxyl groups of citrate [129]. In the presence of $\mathrm{Pb}^{2+}$ ions, the AuNPs aggregated rapidly, which led to the decrease of the Raman intensity of the $v(\mathrm{C}-\mathrm{OH})$ band at $1096 \mathrm{~cm}^{-1}$ accompanied by the solution turning blue. A linear relationship from 50 to $1000 \mathrm{ppt}$ and a low LOD of $25 \mathrm{ppt}$ were obtained. However, the presence of $\mathrm{Hg}^{2+}, \mathrm{Cd}^{2+}$, and $\mathrm{Ni}^{2+}$ ions in the solution will cause certain detection interference. Figure 8 a illustrates the working principle of the detection of lead ions utilizing Ag-coated Au nanoparticles (Au@AgNPs) functionalized with L-cysteine [131]. Upon the addition of $\mathrm{Pb}^{2+}$ ions, metal nanoparticles self-aggregated due to the complexation of $\mathrm{L}$-cysteine and lead ions, which significantly enhanced the SERS signal of 4-ATP which served as a Raman reporter, with an unprecedented LOD of $1 \mathrm{pM}$. In addition, the "turn-off" mode of detection of lead ions has also been reported by Xian's group (Figure 8b) [132]. In their design, CB[7] first formed dimers with AuNPs through carbonyl groups under the action of its rigid barrel-shaped structure. Then, because of the electrostatic interaction between AuNPs capped with negatively charged citrate and graphene decorated with positively charged poly(diallyldimethylammonium chloride), AuNPs/CB agglomerates were attracted to the surface of the water-soluble graphene to form the G/AuNPs/ $\mathrm{CB}$ composites, which produced a huge enhancement effect of $\mathrm{CB}[7]$ due to the location of the center of the "hot spot." When $\mathrm{Pb}^{2+}$ ions were added to the system, $\mathrm{CB}[7]$ complexed with $\mathrm{Pb}^{2+}$ ions and separated from the surface of composites, accompanied a reduction of the SERS signal of CB[7] simultaneously. The proposed novel approach showed a wide linear range from $1 \mathrm{nM}$ to $0.3 \mu \mathrm{M}$ and a LOD of $0.3 \mathrm{nM}$ with high selectivity.

Detection of lead ions with other special assays: In addition to the two assays mentioned above, some special strategies have been applied to determine lead ions. For example, Jiang's group put forward a facile SERS strategy for the analysis of trace lead ions based on aptamer-regulating gold nanoplasmonics (Figure 8c) 
(a)

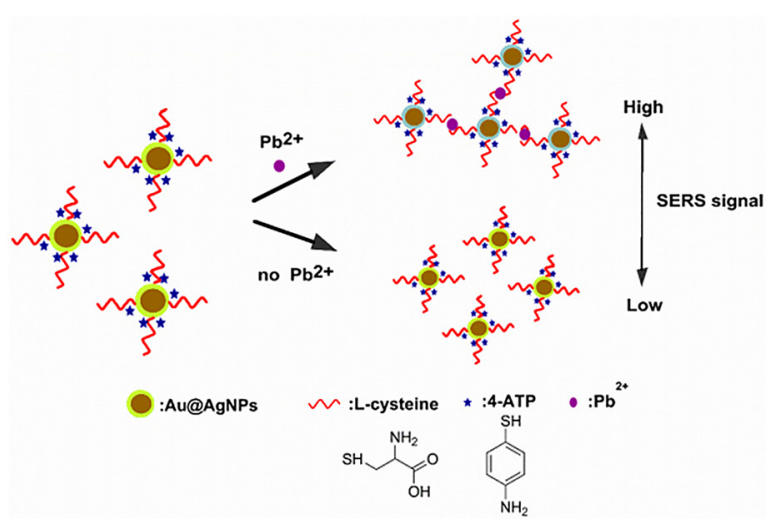

(b)

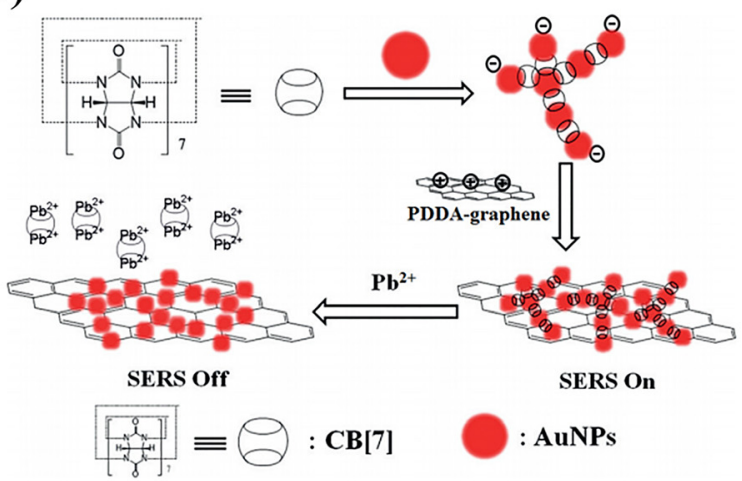

(c)

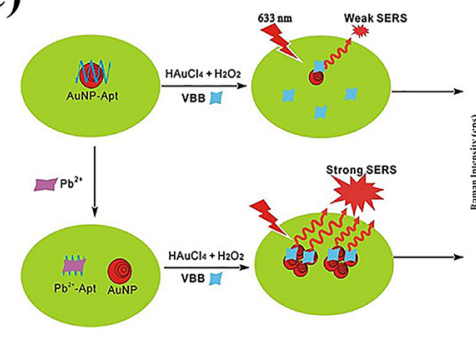

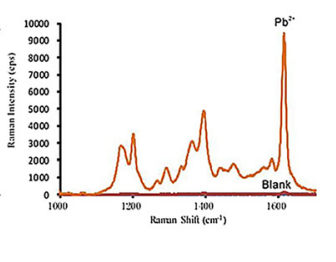

(d)

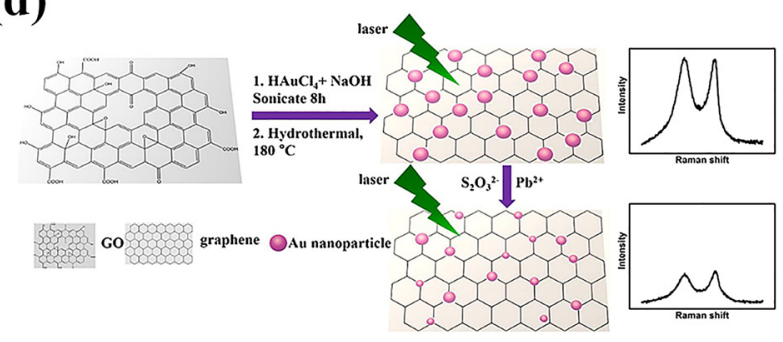

Figure 8: Detection of $\mathrm{Pb}^{2+}$ ions with various special strategies.

(a) Au@AgNPs functionalized with L-cysteine self-aggregated in the presence of $\mathrm{Pb}^{2+}$ ions [131]. (b) $\mathrm{CB}$ [7] complexed with $\mathrm{Pb}^{2+}$ ions and separated from the surface of G/AuNPs/CB composite [132]. (c) AuNP nanozyme accelerated the redox reaction of $\mathrm{HAuCl}_{4}-\mathrm{H}_{2} \mathrm{O}_{2}$ to form more AuNPs [133]. (d) $\mathrm{Pb}^{2+}$ ions sped up the dissolution of AuNPs on the surface of graphene in the presence of $\mathrm{S}_{2} \mathrm{O}_{3}{ }^{2-}$ [135].

[133]. In their report, AuNP nanozyme accelerated the redox reaction of $\mathrm{HAuCl}_{4}-\mathrm{H}_{2} \mathrm{O}_{2}$ to form more AuNPs which resulted in the generation of a strong SERS signal of VBB as a Raman reporter at $1614 \mathrm{~cm}^{-1}$. In the presence of aptamers, it adsorbed to the AuNP surface and formed the AuNP/PbApt complex, which inhibited the catalytic reaction of the nanozyme and reduced the SERS intensity. When $\mathrm{Pb}^{2+}$ ions were added, they bonded specifically to the aptamers to form a stable G-quadruplex structure and released nanozyme that allowed more $\mathrm{HAuCl}_{4}$ to be reduced to AuNPs, accompanied by an increased SERS signal. Afterward, their group did analogous work with graphene oxide nanoribbons [134]. Moreover, Zhao and coworkers took advantage of in situ regulation of the structure of gold nanoparticles/reduced graphene oxide (AuNPs-rGO) colloid to analyze the lead ions quantitatively (Figure 8d) [135]. They first synthesized the AuNPs-rGO colloid by reducing $\mathrm{HAuCl}_{4}$ on graphene oxide nanosheets. In the presence of thiosulfate ions $\left(\mathrm{S}_{2} \mathrm{O}_{3}{ }^{2-}\right)$, lead ions sped up the dissolution of AuNPs on the surface of graphene, which led to a decrease in the number of "hot spots" and a significant reduction of the Raman intensity of the graphene. A novel assay for in situ regulation of nanoarchitecture by $\mathrm{Pb}^{2+}$.

Table 6: Various SERS sensors for $\mathrm{Pb}^{2+}$ ions detection.

\begin{tabular}{llllll}
\hline SERS substrate & Raman reporter & Range & LOD & Comments & Ref. \\
\hline AuNPs & MBA & $20 \mathrm{nM}-1 \mu \mathrm{M}$ & $20 \mathrm{nM}$ & Selective but complicated & [126] \\
Ag-AuNPs@Si & $\mathrm{Cy5}$ & $10 \mathrm{pM}-1 \mu \mathrm{M}$ & $8.9 \mathrm{pM}$ & Sensitive, recyclable but low reproducibility & [127] \\
$\mathrm{Fe}_{3} \mathrm{O}_{4} @ A u @ A g N P s$ & $\mathrm{Cy3}$ & $0.01-1.0 \mathrm{nM}$ & $5 \mathrm{pM}$ & Sensitive, reproducible but complicated & [128] \\
AuNPs & Citrate & $50-1000 \mathrm{ppt}$ & $25 \mathrm{ppt}(0.12 \mathrm{nM})$ & Sensitive, simple but low selectivity, reproducibility & [129] \\
& & $(0.24-4.83 \mathrm{nM})$ & & & \\
Au@AgNPs & 4-ATP & $5 \mathrm{pM}-10 \mathrm{nM}$ & $1 \mathrm{pM}$ & Sensitive, simple but low reproducibility \\
G/AuNPs/CB composites & $\mathrm{CB}[7]$ & $1 \mathrm{nM}-0.3 \mu \mathrm{M}$ & $0.3 \mathrm{nM}$ & Novel, sensitive but low reproducibility \\
AuNPs & VBB & $6.66-33.3 \mu \mathrm{M}$ & - & Selective, simple but low reproducibility & [131] \\
GONRs & VBB & $0.002-0.075 \mu \mathrm{M}$ & $0.7 \mathrm{nM}$ & Sensitive but not novel & [133] \\
AuNPs-rGO & $\mathrm{rGO}$ & $5 \mathrm{nM}-4 \mu \mathrm{M}$ & $1 \mathrm{nM}$ & Novel, rapid but low reproducibility & [134] \\
\hline
\end{tabular}


enhanced gold leaching reaction was established with a good linear relationship from $5 \mathrm{nM}$ to $4 \mu \mathrm{M}$ and a low LOD of $1 \mathrm{nM}$. Table 6 gives a list of various SERS sensors for $\mathrm{Pb}^{2+}$ ions' detection.

\subsection{Detection of chromium(VI)}

Metallic chromium has two common valence states: trivalent chromium and hexavalent chromium. Trivalent chromium is a necessary trace element in the body and plays an irreplaceable role in the metabolism of sugar and fat [136]. Hexavalent chromium, as one of the common pollutants in water, is much more toxic than trivalent chromium, which can lead to cancer, skin disease, respiratory damage, and gastrointestinal problems when concentrated in the human body [137]. Chromium ions are usually found in the form of chromate(VI), which can be detected directly through the symmetric stretching vibrations of the $\mathrm{Cr}-\mathrm{O}$ band at around $796 \mathrm{~cm}^{-1}$. Moreover, chromium ions can also be complexed with functional groups or reduced to trivalent chromium accompanied by the change of the Raman signal, which is used as a foundation for the quantitative detection of chromium ions.

Direct detection of chromium(VI). In recent years, many research groups have been devoted to developing stable and efficient SERS substrates to concentrate and detect $\mathrm{Cr}(\mathrm{VI})$. For example, Du et al. synthesized a highly sensitive, uniform, and recyclable $\mathrm{Fe}_{3} \mathrm{O}_{4} @ \mathrm{Ag}$ substrate to determine the chromium(VI) in water samples via the $\mathrm{Cr}-\mathrm{O}$ bond [138]. The SERS intensity and $\mathrm{Cr}(\mathrm{VI})$ concentration presented a good linear dependence relationship between 5 and $100 \mathrm{ppb}$. However, some coexisting ions such as sulfates, nitrates, and chlorides produced interference for SERS analysis. Similarly, Jing's group put forward a multifunctional satellite $\mathrm{Fe}_{3} \mathrm{O}_{4}-\mathrm{Au} @ \mathrm{TiO}_{2}$ substrate for detection and photoreduction of $\mathrm{Cr}(\mathrm{VI})$ (Figure 9a) [139]. Compared with the $\mathrm{Fe}_{3} \mathrm{O}_{4} @ \mathrm{Ag}$ structure, the proposed substrate can not only detect $\mathrm{Cr}(\mathrm{VI})$ with evident sensitivity lasting 30 days but also observe the reduction of $\mathrm{Cr}(\mathrm{VI})$ at $788 \mathrm{~cm}^{-1}$ in situ in the presence of $\mathrm{TiO}_{2}$. The LOD reached $0.05 \mu \mathrm{M}$.

Detection of chromium(VI) with other special strategies: In addition to direct detection methods, some indirect approaches have also been reported. For instance, $\mathrm{Xu}$ et al. achieved the detection of $\mathrm{Cr}(\mathrm{VI})$ in an aqueous solution via the semiconductor-driven SERS sensor [140]. Different from other conventional strategies, this method used a semiconductor substrate instead of a traditional noble metal substrate, proving that the semiconductor also had a surface enhancement effect. In their design, Alizarin red S (ARS), as a Raman probe, was modified on the colloidal $\mathrm{TiO}_{2}$ nanoparticles through the strong electronic coupling between them. The ARS- $\mathrm{TiO}_{2}$ composite substrate was sensitive to the concentration of $\mathrm{Cr}(\mathrm{VI})$. With the increase of the concentration of $\mathrm{Cr}(\mathrm{VI})$, more ARS was degraded, resulting in reducing the Raman signal. Semiconductor $\mathrm{TiO}_{2}$ not only acted as an active substrate to excite the SERS signal of ARS molecules but also as a catalytic site to induce the selfdegradation reaction of ARS to $\mathrm{Cr}(\mathrm{VI})$, which shed new light (a)

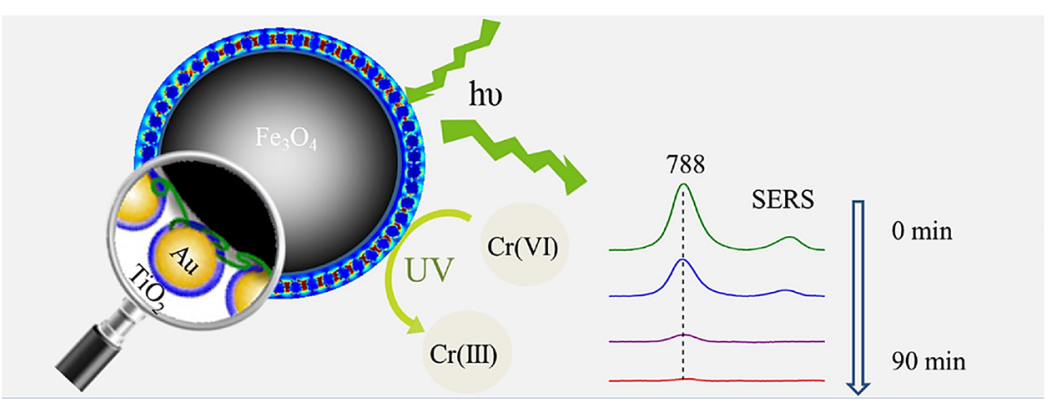

(b)

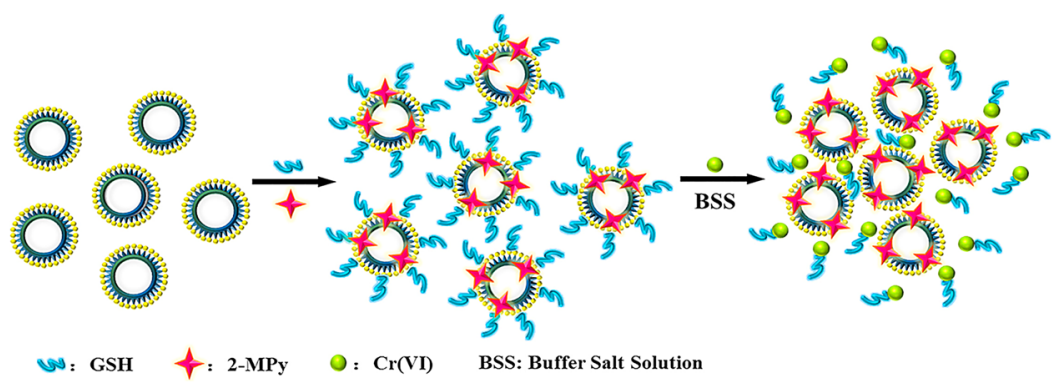

Figure 9: SERS-based chromium(VI) detection.

(a) Direct detection of $\mathrm{Cr}(\mathrm{VI})$ based on the characteristic peak at $788 \mathrm{~cm}^{-1}$ using $\mathrm{Fe}_{3} \mathrm{O}_{4}-\mathrm{Au} @ \mathrm{TiO}_{2}$ substrate [139]. (b) GSH bonding with $\mathrm{Cr}(\mathrm{VI})$ to form $\mathrm{Cr}(\mathrm{VI})-\mathrm{GSH}$ complexes [141]. 
on practical applications. The lowest detectable concentration is $0.6 \mu \mathrm{M}$. In 2017, Zhou et al. synthesized a hollow sea urchin-like $\mathrm{TiO}_{2} @ \mathrm{Ag}$ nanoparticle decorated with GSH and 2-mercaptopyridine (2-MPy) as a Raman reporter to specifically analyze $\mathrm{Cr}(\mathrm{VI})$ [141]. The working principle for $\mathrm{Cr}(\mathrm{VI})$ detection is depicted in Figure 9b. A buffer solution with a certain concentration will destabilize the structure of $\mathrm{TiO}_{2} @ A g N P s$ and cause it to aggregate. When GSH was immobilized on the $\mathrm{TiO}_{2} @ A g N P s$ ' surface via the Ag-S bond, it can effectively prevent the aggregation of nanoparticles and make them uniformly dispersed. Upon the addition of $\mathrm{Cr}(\mathrm{VI})$, GSH bonds with $\mathrm{Cr}(\mathrm{VI})$ to form $\mathrm{Cr}(\mathrm{VI})$ GSH complexes, which induced the aggregation of nanoparticles in the presence of buffer salt solution. The proposed sensor showed excellent linearity ranging from $10 \mathrm{nM}$ to $2 \mu \mathrm{M}$ with a low LOD of $1.45 \mathrm{nM}$. In 2018, Tian's group found that carbimazole modified sodium alginate (SA)protected AgNPs could achieve the aim of the indirect detection of $\mathrm{Cr}(\mathrm{VI})$ [142]. Carbimazole, as a Raman reporter, has hydrolytic products that adsorbed on the surface of SAAgNPs and the system aggregated in the presence of $\mathrm{NaCl}$ solution, which produced a strong SERS signal at $504 \mathrm{~cm}^{-1}$. When $\mathrm{Cr}(\mathrm{VI})$ was added, the hydrolytic products of carbimazole reacted with $\mathrm{Cr}(\mathrm{VI})$ and generated a disulfide compound, resulting in the reduction of SERS intensity at $504 \mathrm{~cm}^{-1}$. The area change of the SERS peak was proportional to the $\mathrm{Cr}(\mathrm{VI})$ concentration over 1.71-171 $\mathrm{nM}$ with a low LOD of $1.01 \mathrm{nM}$. Table 7 lists the SERS-based methods for the determination of $\mathrm{Cr}(\mathrm{VI})$.

\subsection{Dual or triple channel to detect heavy metal ions}

In recent years, to obtain more reliable and more accurate results, SERS combined with other technologies such as colorimetry, fluorescence and microextraction have been reported for the detection of heavy metal ions. The combination of these techniques can complement each other and make the detection results more convincing.

For example, Zhang et al. demonstrated a colorimetric and SERS dual-mode strategy for the determination of $\mathrm{Pb}^{2+}$ based on $\mathrm{Au}-\mathrm{Ag}$ core-shell nanoparticles functionalized with gluconate ion (Gluc) and 2-naphthalenethiol (2-NT) (Figure 10a) [130]. In the presence of $\mathrm{Pb}^{2+}$ ions, the adsorbed Gluc complexed with $\mathrm{Pb}^{2+}$ ions, inducing the aggregation of 2-NT@Au@AgNPs, which exhibited a significant change in the color and SERS intensity of 2-NT correspondingly. The LOD was down to $0.252 \mu \mathrm{M}$ and $0.185 \mathrm{pM}$ for the colorimetry and SERS methods, respectively. Another colorimetry/SERS dual-channel sensor for trace analysis of $\mathrm{Cu}^{2+}$ was constructed by Deng's group (Figure 10b) [143]. In their design, MBA and 4-MPY, which both served as Raman reporters, were immobilized on the surface of AgNPs and AuNPs, respectively. Upon the addition of $\mathrm{Cu}^{2+}$, pyridyl nitrogen and carboxy group specifically bond with $\mathrm{Cu}^{2+}$ ions to form AgNPs- $\mathrm{Cu}^{2+}-\mathrm{AuNPs}$ core-satellite structures, which induced the aggregation of NPs, leading to the appearance of a new absorption peak at $730 \mathrm{~nm}$ and the increase of SERS signal at 1224 and $1429 \mathrm{~cm}^{-1}$. The UV-vis and SERS methods both displayed a good linear response from 0.1 to $200 \mu \mathrm{M}$ and $1 \mathrm{pM}$ to $100 \mu \mathrm{M}$ with a LOD of $0.032 \mu \mathrm{M}$ and $0.6 \mathrm{pM}$, respectively.

The combination of SERS and fluorescence was also very popular. For instance, Li et al. developed a fluorescent/SERS dual-sensor consisting of AuNPs functionalized with $N$-(2(bis(pyridine-2-ylmethyl)amino)ethyl)-2-mercaptoacetamide (MDPA) for the detection and imaging of intracellular $\mathrm{Zn}^{2+}$ ions (Figure 11a) [144]. On account of the coordination between MDPA-AuNPs and $\mathrm{Zn}^{2+}$ ions, the fluorescence intensity was enhanced because of the chelation-enhanced fluorescence effect and the Raman signal was amplified due to the $\mathrm{Zn}^{2+}$-triggered self-aggregation of MDPA-AuNPs. The LODs of the fluorescence and SERS methods were $0.32 \mu \mathrm{M}$ and $0.28 \mathrm{pM}$, which were far lower than the concentration required by the EPA in drinkable water. In 2018, Makam and coworkers fabricated an ultrasensitive fluorescence and SERS dual-sensor platform for the determination of trace $\mathrm{Hg}^{2+}$ ions based on a bolaamphiphile (HPH) as a dual-responsive probe (Figure 11b) [145]. HPH, consisting of histidine and an $\alpha$-amino acid with an imidazole functional group, is considered a strong $\mathrm{Hg}^{2+}$ chelator and a Raman reporter. When $\mathrm{Hg}^{2+}$ ions were added, HPH quickly coordinated with $\mathrm{Hg}^{2+}$ to form ordered host-guest complexes, which induced

Table 7: SERS-based methods for the determination of $\mathrm{Cr}(\mathrm{VI})$.

\begin{tabular}{|c|c|c|c|c|c|}
\hline SERS substrate & Raman reporter & Range & LOD & Comments & Ref. \\
\hline $\mathrm{Fe}_{3} \mathrm{O}_{4} @ \mathrm{Ag}$ & - & 5-100 ppb $(96 \mathrm{nM}-1.92 \mu \mathrm{M})$ & $5 \mathrm{ppb}(96 \mathrm{nM})$ & Sensitive, reliable but low anti-interference & [138] \\
\hline $\mathrm{Fe}_{3} \mathrm{O}_{4}-\mathrm{Au} @ \mathrm{TiO}_{2}$ & - & $0-5 \mu \mathrm{M}$ & $0.05 \mu \mathrm{M}$ & Versatile, selective but low reproducibility & [139] \\
\hline $\mathrm{TiO}_{2} \mathrm{NPS}$ & ARS & $0.6-10 \mu \mathrm{M}$ & $0.6 \mu \mathrm{M}$ & Simple, selective but low sensitivity & [140] \\
\hline $\mathrm{TiO}_{2} @ A g N P s$ & 2-MPy & $10 \mathrm{nM}-2 \mu \mathrm{M}$ & $1.45 \mathrm{nM}$ & Sensitive, recyclable but low reproducibility & [141] \\
\hline SA-AgNPs & Carbimazole & $1.71-171 \mathrm{nM}$ & $1.01 \mathrm{nM}$ & Facile, sensitive but low reproducibility & [142] \\
\hline
\end{tabular}


(a)

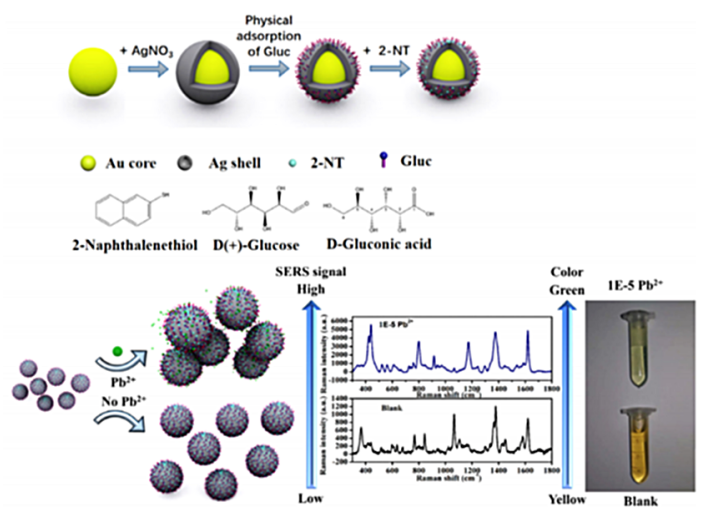

(b)

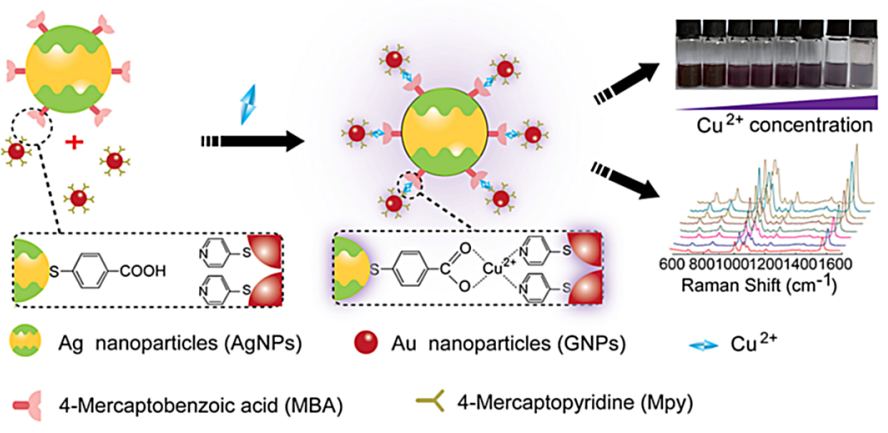

Figure 10: Colorimetric and SERS dual-mode strategies for the detection of heavy metal ions.

(a) A colorimetric and SERS dual-mode strategy for the determination of $\mathrm{Pb}^{2+}$ ions based on Au@AgNPs functionalized with Gluc and 2-NT [130].

(b) Colorimetry/SERS dual-channel sensor for trace analysis of $\mathrm{Cu}^{2+}$ ions based on AgNPs-Cu+2+-GNPs core-satellite structures [143].

quenching of the fluorescence and enhancement of the SERS signal. The LOD of the SERS method reached an unexpected $60 \mathrm{aM}\left(60 \times 10^{-18} \mathrm{M}\right)$, which is 10 orders of magnitude lower than the concentration required by the USEPA. Moreover, a colorimetric/fluorescent/SERS triple-mode sensor for $\mathrm{Cu}^{2+}$ detection based on binaphthalene (BAMH)-modified $\mathrm{Au}$ nanorods (AuNRs@BAMH) was built by Deng's group (Figure 11c) [146]. In their design, the Schiff-base and phenolic hydroxyl functional group of BAMH had a strong affinity for copper ions to form complexes, which not only quenched the fluorescence intensity and enhanced the colorimetric response of AuNRs@BAMH but also increased the SERS signal and induced the appearance of a new peak due to the self-aggregation of AuNRs. The detection limits of the triple-channel sensor were $3.0 \mathrm{nM}, 0.42 \mathrm{nM}$, and $0.38 \mathrm{pM}$.

The co-working of SERS and microextraction was developed for chromium(VI) speciation in practical samples such as food and wastewater [147]. This working principle is exhibited in Figure 11d. Briefly, R6G, as a common Raman probe, has a strong SERS signal at $1505 \mathrm{~cm}^{-1}$ attributed to a C-C stretching vibration. After introducing the $\mathrm{CrO}_{3} \mathrm{Cl}^{-}$, the cationic $\mathrm{R} 6 \mathrm{G}[\mathrm{RG}]^{+}$ was extracted in the organic phase and formed the ion associate $\left[\mathrm{RG}^{+} . \mathrm{CrO}_{3} \mathrm{Cl}^{-}\right]$complex in an acidic environment. When the extracted phase was detected on the nanoflower-shaped silver substrate, the SERS signal of R6G was obviously weakened due to the formation of $\left[\mathrm{RG}^{+} \cdot \mathrm{CrO}_{3} \mathrm{Cl}^{-}\right]$. The analytical assay shows a detection limit of $0.03 \mathrm{ppb}$.

\subsection{The simultaneous detection of multiple heavy metal ions}

In complex environmental systems, there is often more than one kind of heavy metal ion. Under the condition of noninterference, if multiple heavy metal ions can be detected at the same time, it will not only save time and labor but also have greater development potential in practical applications. Therefore, it is particularly important to develop stable and repeatable SERS sensors for the simultaneous determination of multiple heavy metal ions in actual samples detection.

In 2015, the simultaneous detection of $\mathrm{Hg}^{2+}$ and $\mathrm{Ag}^{+}$ ions using a SERS sensor based on AuNP trimers encoded with triple Raman labels was put forward by Kuang's group (Figure 12a) [59]. First, they functionalized the AuNPs with three ssDNA molecules (DNA1, DNA2, and DNA3). DNA4 and DNA5, which were complementary to DNA3, were added to construct a "Y-shaped" DNA skeleton on the AuNP-DNA3 surface. Then, three kinds of Raman reporters were immobilized on DNA1, -2 , and -3 to form AuNP-DNA1@ATP, AuNP-DNA2@NTP, and AuNPDNA3@MATT self-assembled monolayers. Upon the addition of $\mathrm{Hg}^{2+}$ or $\mathrm{Ag}^{+}$ions, the AuNP dimers were built up via the $\mathrm{C}-\mathrm{Ag}^{+}-\mathrm{C}$ and $\mathrm{T}-\mathrm{Hg}^{2+}-\mathrm{T}$ structures. When two ions coexisted, the AuNP trimers were assembled accompanied by a significant signal enhancement of the three Raman probes which were clearly distinguished due to the generation of lots of "hot spots." The LODs of $\mathrm{Hg}^{2+}$ and $\mathrm{Ag}^{+}$ions were down to 8.57 and $8.43 \mathrm{pM}$, respectively. In addition, Shi et al. first achieved the simultaneous detection of $\mathrm{Pb}^{2+}$ and $\mathrm{Hg}^{2+}$ ions using reproducible silicon nanohybrid substrates based on the $\mathrm{Pb}^{2+}$-dependent DNAzyme and $\mathrm{T}-\mathrm{Hg}^{2+}-\mathrm{T}$ structure [148]. As illustrated in Figure 12b, the two DNA sequences were modified on the surface of Si@AgNPs. One sequence was an ssDNA labeled with FAM (carboxyfluorescein) which consists of consecutive T bases (HS-B1-FAM) for the determination of $\mathrm{Hg}^{2+}$. The other sequence was a dsDNA marked with ROX 
(a)
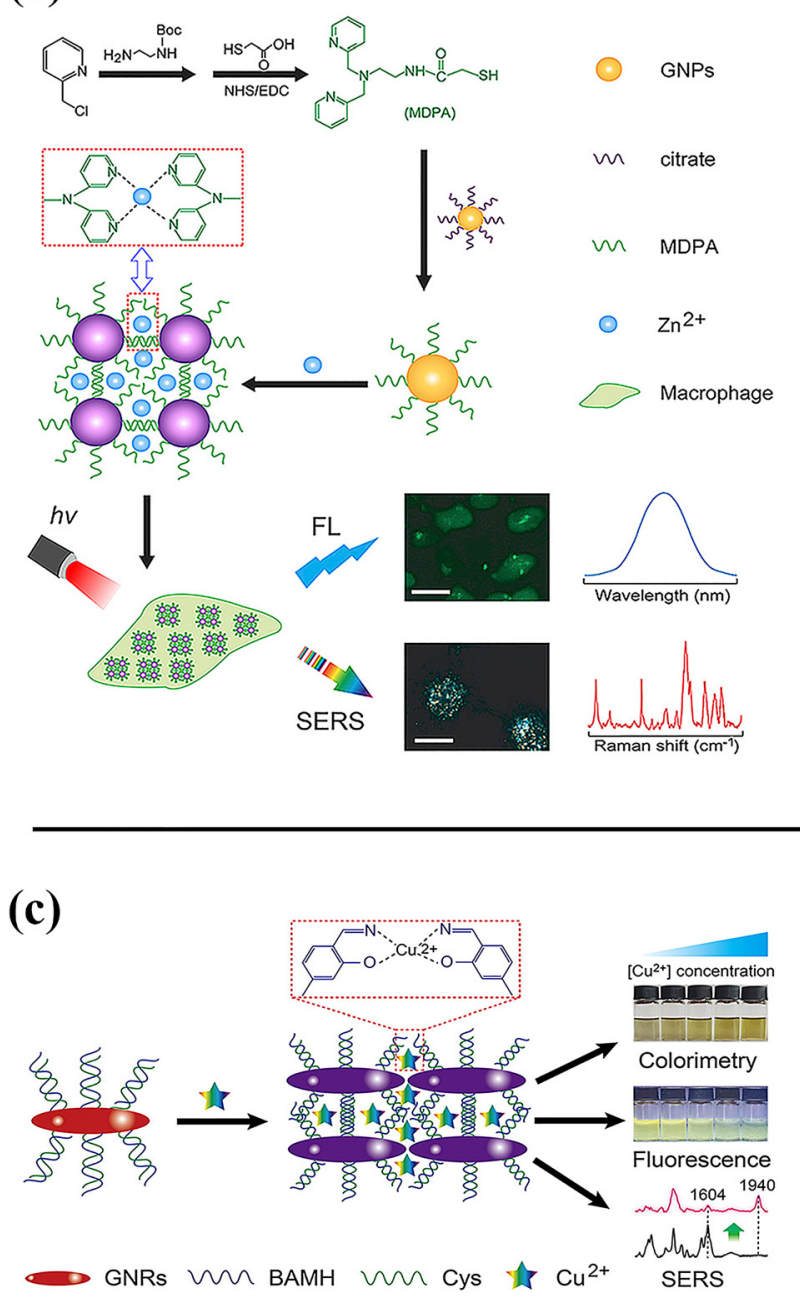

(b)
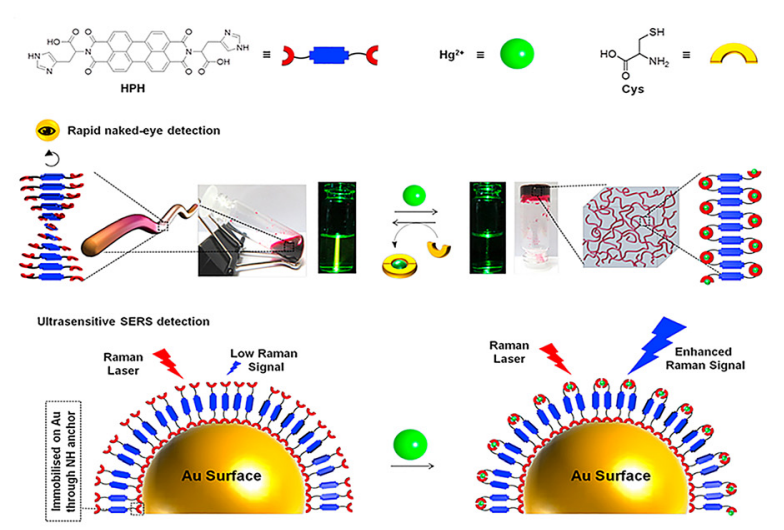

(d)

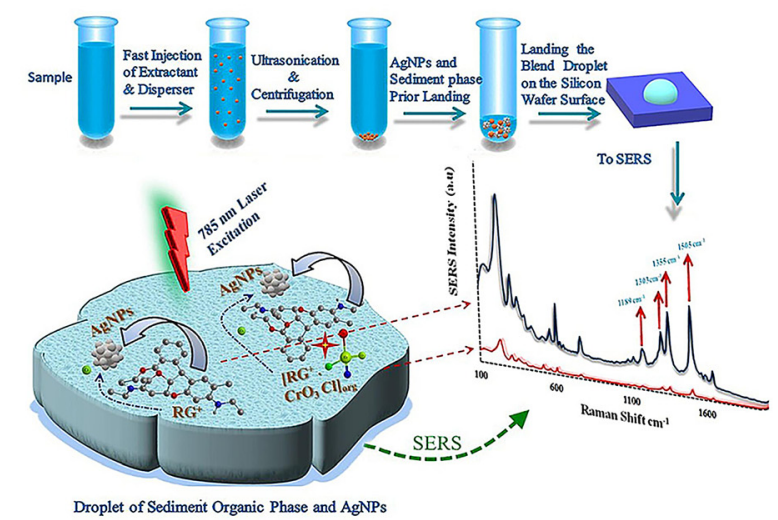

Figure 11: The combination of SERS and fluorescence (microextraction) techniques for the detection of heavy metal ions.

(a) $\mathrm{Zn}^{2+}$ triggered the self-aggregation of MDPA-AuNPs [144]. (b) An ultrasensitive fluorescence and SERS dual-sensor platform for the determination of trace $\mathrm{Hg}^{2+}$ ions based on HPH as a dual-responsive probe [145]. (c) A colorimetric/fluorescent/SERS triple-mode sensor for $\mathrm{Cu}^{2+}$ ions' detection based on AuNRs@BAMH [146]. (d) The co-working of SERS and microextraction for chromium(VI) speciation [147].

(6-carboxy-X-rhodamine), containing a $\mathrm{Pb}^{2+}$-dependent DNAzyme strand (HS-17E-ROX) and its complementary strand (17DS) for detection of $\mathrm{Pb}^{2+}$ ions. An OR logic gate that can be activated in the presence of $\mathrm{Pb}^{2+}$ and $\mathrm{Hg}^{2+}$ was established according to the schematic. In the absence of $\mathrm{Pb}^{2+}$ and $\mathrm{Hg}^{2+}$ ions, there was a weak Raman signal owing to the Raman probes being far away from the substrate (an input $(0,0)$ ). When $\mathrm{Pb}^{2+}$ or $\mathrm{Hg}^{2+}$ ions were added to the system, the 17DS was cleaved by the HS-17E-ROX due to the formation of a complex between the $\mathrm{Pb}^{2+}$ and $\mathrm{Pb}^{2+}$ dependent DNAzyme strand, or the $\mathrm{T}-\mathrm{Hg}^{2+}-\mathrm{T}$ hairpin structure was built because of the stronger affinity between $\mathrm{Hg}^{2+}$ and $\mathrm{T}$ base pairs, resulting in ROX or FAM approaching the substrate accompanied with the increase of SERS signal (an input $(0,1)$ or an input $(1,0)$ ). Upon the addition of both $\mathrm{Pb}^{2+}$ and $\mathrm{Hg}^{2+}$ ions, the Raman peaks of 4-ATP which were selected as internal standard, ROX and FAM were observed without interference (an input $(1,1)$ ). The simultaneous detection of $\mathrm{Pb}^{2+}$ and $\mathrm{Hg}^{2+}$ ions strategies exhibited a wide linear range from $100 \mathrm{pM}$ to $10 \mu \mathrm{M}$ and from $1 \mathrm{nM}$ to $10 \mu \mathrm{M}$ with low LODs of 19.8 and $168 \mathrm{ppt}$, respectively. 
(a)

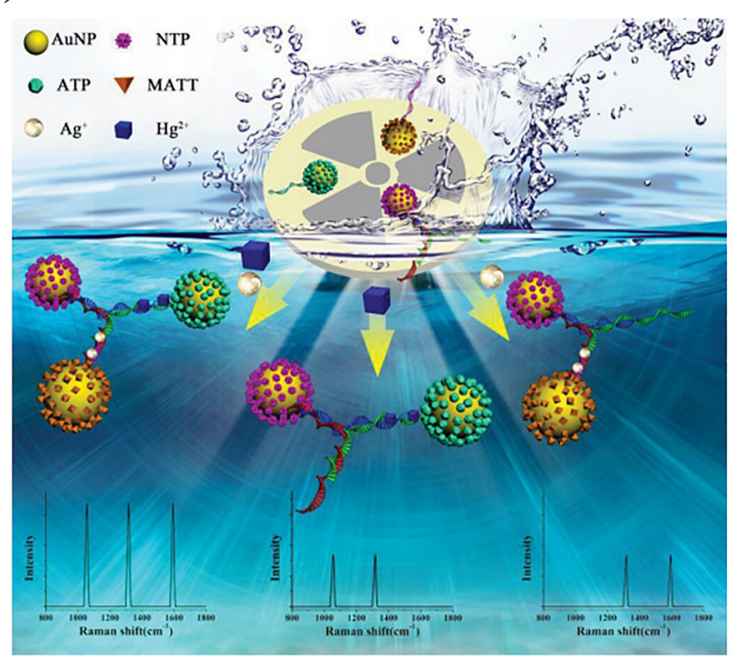

(b)

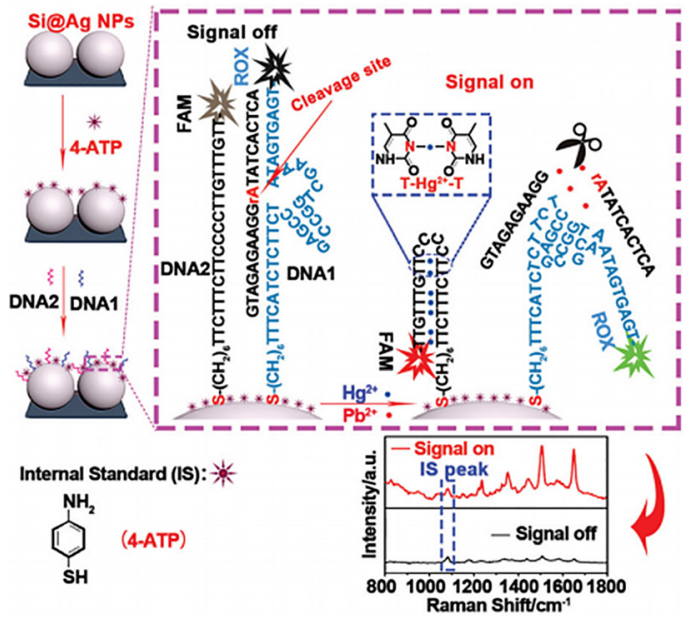

Figure 12: SERS sensors for simultaneous determination of multiple heavy metal ions.

(a) Simultaneous detection of $\mathrm{Hg}^{2+}$ and $\mathrm{Ag}^{+}$ions SERS sensor based on gold nanoparticle trimers encoded with triple Raman labels [59]. (b) Simultaneous detection of $\mathrm{Pb}^{2+}$ and $\mathrm{Hg}^{2+}$ ions using reproducible silicon nanohybrid substrates based on the $\mathrm{Pb}^{2+}$-dependent DNAzyme and T$\mathrm{Hg}^{2+}-\mathrm{T}$ structure [148].

\section{Conclusions and perspectives}

On account of the widespread phenomenon of heavy metal pollution, the development of rapid, efficient, low-cost detection methods is urgent. SERS technology is considered as one of the most promising means for the detection of heavy metal ions in recent years. This review summarized the recent advances in detecting several common heavy metal ions based on the SERS method which can be mainly divided into the following strategies: (1) like arsenate, arsenite, and dichromate, they can be tested directly by As-O or $\mathrm{Cr}-\mathrm{O}$ bonds. (2) According to the acid-base theory, most of the heavy metal ions were able to coordinate specifically with $\mathrm{N}, \mathrm{O}$, or $\mathrm{S}$ atoms, which results in a change of the SERS signal. (3) Some heavy metal ions form stable structures with certain groups such as $\mathrm{C}-\mathrm{Ag}^{+}-\mathrm{C}$ and $\mathrm{T}-\mathrm{Hg}^{2+}-\mathrm{T}$ structures. (4) Certain heavy metal ions like $\mathrm{As}^{3+}$ or $\mathrm{Pb}^{2+}$ are capable of hybridization with aptamer or DNAzyme. (5) Some heavy metal ions like $\mathrm{Cu}^{2+}$ and $\mathrm{Pb}^{2+}$ have a certain catalytic effect on chemical reactions. (6) Other special strategies.

Although SERS-based technology has achieved satisfactory progress in heavy metal ions' detection, it still faces a series of challenges at this stage: (1) it is well known that the reproducibility of the Raman signal is low, and metal nanoparticles are prone to nonspecific aggregation under the influence of the external environment, so the development of a stable, uniform and reproducible SERS substrate is the crucial factor of SERS technology. (2) Because trace heavy metal ions pose a great threat to the human body and environment, it is very necessary to improve further the sensitivity of SERS technology. (3) Because most heavy metal ions can coordinate with $\mathrm{N}, \mathrm{O}$, and $\mathrm{S}$ atoms, it is important to pay attention to the selectivity of the method and the interference of coexisting ions when utilizing this principle, especially complicated samples. (4) At present, SERS technology basically stays as a laboratory test, which still has a big challenge for the quantitative testing on-site and actual complex samples, so it cannot be regarded as one of the conventional detection assays. (5) The high cost and large bulk of Raman instruments limit their field applications, while portable Raman instruments are relatively insensitive, so manufacturing more precise and convenient Raman instruments is an ongoing challenge.

With the development of the science and technology, SERS combined with other technologies such as fluorescence, colorimetry, microfluidics, microextraction, immunoassay, and DFT for detecting heavy metal ions are more and more favored by researchers. On the one hand, other technologies are able to make up for the shortcomings of SERS. On the other hand, the co-working of the two or three technologies makes the results more convincing. In actual samples, multiple heavy metal ions often coexist, so the simultaneous detection of multiple heavy metal ions without interference is also an important direction for future development. Moreover, the cost and size of Raman instruments will be the focus of future attention because 
the most important aspect of heavy metal ion detection is field testing.

In summary, SERS technology exhibited a satisfactory application prospect in the detection of heavy metal ions, and it is hoped to develop more maturity in the future and become one of the mainstream detection methods.

Author contribution: All the authors have accepted responsibility for the entire content of this submitted manuscript and approved submission.

Research funding: This work was supported by the National Natural Science Foundation of China (Grant No. 11974152 and 21671089), the LiaoNing Revitalization Talents Program (Grant No. XLYC1807162), the Shenyang High-level Innovative Talents Program (Grant No. RC200565), the Natural Science Foundation of Liaoning Province (Grant No. 2020-YKLH-22), the Scientific research projects of Liaoning Provincial Department of Education (Grant No. L2020002), the Science program of Liaoning Provincial Department of Education (LJKZ0097), the Intercollegiate cooperation project of colleges and universities of Liaoning Provincial Department of Education.

Conflict of interest statement: The authors declare no conflicts of interest regarding this article.

\section{References}

[1] N. K. Srivastava and C. B. Majumder, "Novel biofiltration methods for the treatment of heavy metals from industrial wastewater," J. Hazard Mater., vol. 151, no. 1, pp. 1-8, 2008.

[2] K. Kadirvelu, K. Thamaraiselvi, and C. Namasivayam, "Removal of heavy metals from industrial wastewaters by adsorption onto activated carbon prepared from an agricultural solid waste," Bioresour. Technol., vol. 76, no. 1, pp. 63-65, 2001.

[3] S. Thakur, L. Singh, Z. A. Wahid, M. F. Siddiqui, S. M. Atnaw, and M. F. M. Din, "Plant-driven removal of heavy metals from soil: uptake, translocation, tolerance mechanism, challenges, and future perspectives," Environ. Monit. Assess., vol. 188, pp. 206-216, 2016.

[4] P. B. Tchounwou, W. K. Ayensu, N. Ninashvili, and D. Sutton, "Environmental exposure to mercury and its toxicopathologic implications for public health," Environ. Toxicol., vol. 18, no. 3, pp. 149-175, 2010.

[5] E. M. Nolan and S. J. Lippard, "Tools and tactics for the optical detection of mercuric ion," Chem. Rev., vol. 108, no. 50, pp. 3443-3480, 2008.

[6] B. B. Rodriguez, J. A. Bolbot, and I. E. Tothill, "Development of urease and glutamic dehydrogenase amperometric assay for heavy metals screening in polluted samples," Biosens. Bioelectron., vol. 19, no. 10, pp. 1157-1167, 2004.

[7] P. S. Donnelly, Z. Xiao, and A. G. Wedd, "Copper and Alzheimer's disease," Curr. Opin. Chem. Biol., vol. 11, no. 2, pp. 128-133, 2007.
[8] National Primary Drinking Water Regulations. Available at: https://www.epa.gov/ground-water-and-drinking-water/ national-primary-drinking-water- regulations\#one.

[9] H. Li, J. Zhao, S. F. Zhao, and G. F. Cui, "Simultaneous determination of trace $\mathrm{Pb}(\mathrm{II}), \mathrm{Cd}(\mathrm{II})$, and $\mathrm{Zn}$ (II) using an integrated three-electrode modified with bismuth film," Microchem. J., vol. 168, p. 106390, 2021.

[10] H. C. Ma, R. An, L. L. Chen, et al., "A study of the photodeposition over $\mathrm{Ti} / \mathrm{TiO}_{2}$ electrode for electrochemical detection of heavy metal ions," Electrochem. Commun., vol. 57, pp. 18-21, 2015.

[11] K. B. S. Perelonia, K. C. D. Benitez, R. J. S. Banicod, G. C. Tadifa, F. D. Cambia, and U. M. Montojo, "Validation of an analytical method for the determination of cadmium, lead and mercury in fish and fishery resources by graphite furnace and cold vapor atomic absorption spectrometry," Food Control, vol. 130, p. 108363, 2021.

[12] X. Y. Liu, K. Yu, H. Zhang, et al., “A portable electromagnetic heating-microplasma atomic emission spectrometry for direct determination of heavy metals in soil," Talanta, vol. 219, p. 121348, 2020.

[13] J. Xue, S. F. Gong, X. M. Wang, Y. L. Fan, and X. Li, "Determination of $\mathrm{Hg}, \mathrm{As}, \mathrm{Pb}$, and $\mathrm{Cd}$ in orchard soils by sequential injection vapor generation atomic fluorescence spectrometry," Anal. Lett., vol. 45, no. 15, pp. 2257-2268, 2012.

[14] Z. H. Fernández, J. R. E. Álvarez, A. M. Álvarez, et al., “Metal contaminants in rice from Cuba analyzed by ICP-MS, ICP-AES and CVAAS," Food Addit. Contam. B, vol. 14, no. 1, pp. 59-65, 2021.

[15] T. Balaji, S. A. El-Safty, H. Matsunaga, T. Hanaoka, and F. Mizukami, "Optical sensors based on nanostructured cage materials for the detection of toxic metal ions," Angew. Chem. Int. Ed., vol. 45, no. 43, pp. 7202-7208, 2006.

[16] M. R. Knecht and M. Sethi, "Bio-inspired colorimetric detection of $\mathrm{Hg}^{2+}$ and $\mathrm{Pb}^{2+}$ heavy metal ions using Au nanoparticles," Anal. Bioanal. Chem., vol. 394, pp. 33-46, 2009.

[17] J. Plácido, S. Bustamante-López, K. E. Meissner, D. E. Kelly, and S. L. Kelly, "Microalgae biochar-derived carbon dots and their application in heavy metal sensing in aqueous systems," Sci. Total Environ., vol. 656, pp. 531-539, 2019.

[18] H. N. Kim, W. X. Ren, J. S. Kim, and J. Yoon, "Fluorescent and colorimetric sensors for detection of lead, cadmium, and mercury ions," Chem. Soc. Rev., vol. 41, no. 8, pp. 3210-3244, 2012.

[19] J. Qvarnström, L. Lambertsson, S. Havarinasab, P. Hultman, and W. Frech, "Determination of methylmercury, ethylmercury, and inorganic mercury in mouse tissues, following administration of thimerosal, by species-specific isotope dilution GC-inductively coupled plasma-MS," Anal. Chem., vol. 75, no. 16, pp. 4120-4124, 2003.

[20] S. Ichinoki, N. Kitahata, and Y. Fujii, "Selective determination of mercury(II) ion in water by solvent extraction followed by reversed-phase HPLC," J. Liq. Chromatogr. Relat. Technol., vol. 27, no. 11, pp. 1785-1798, 2004.

[21] M. Fan, G. F. S. Andrade, and A. G. Brolo, "A review on recent advances in the applications of surface-enhanced Raman scattering in analytical chemistry," Anal. Chim. Acta, vol. 1097, pp. 1-29, 2020.

[22] L. Jiang, M. M. Hassan, S. Ali, H. H. Li, R. Sheng, and Q. S. Chen, "Evolving trends in SERS-based techniques for food quality and 
safety: a review," Trends Food Sci. Technol., vol. 112, pp. 225-240, 2021.

[23] C. Song, J. Li, Y. Sun, et al., "Colorimetric/SERS dual-mode detection of mercury ion via SERS-active peroxidase-like Au@AgPt NPs," Sens. Actuators, B, vol. 310, pp. 127849-127856, 2020.

[24] F. Li, J. Wang, Y. Lai, et al., "Ultrasensitive and selective detection of copper (II) and mercury (II) ions by reporter-coded silver nanoparticle-based SERS probes," Biosens. Bioelectron., vol. 39, pp. 82-87, 2013.

[25] F. Cheng, H. Xu, C. Wang, Z. Gong, and M. Fan, "Surfaceenhanced Raman scattering fiber optic sensor as an ion selective optrode: the example of $\mathrm{Cd}^{2+}$ detection," RSC $A d v$., vol. 4, no. 110, pp. 64683-64687, 2014.

[26] Y. Wu, C. Fu, J. Xiang, Y. Cao, and W. Shi, ““'Signal-on” SERS sensing platform for highly sensitive and selective $\mathrm{Pb}^{2+}$ detection based on catalytic hairpin assembly," Anal. Chim. Acta, vol. 1127, pp. 106-113, 2020.

[27] G. Brackx, D. Guinoiseau, L. Duponchel, A. Gélabert, and G. Charron, "A frugal implementation of Surface Enhanced Raman Scattering for sensing $\mathrm{Zn}^{2+}$ in freshwaters-in depth investigation of the analytical performances," Sci. Rep., vol. 10, pp. 1883-1893, 2020.

[28] L. Song, K. Mao, X. Zhou, and J. Hu, "A novel biosensor based on Au@Ag core-shell nanoparticles for SERS detection of arsenic (III)," Talanta, vol. 146, pp. 285-290, 2016.

[29] P. A. Mosier-Boss and M. D. Putnam, "Detection of hexavalent chromium using gold/4-(2-mercaptoethyl) pyridinium surface enhanced Raman scattering-active capture matrices," Anal. Chim. Acta, vol. 801, pp. 70-77, 2013.

[30] Z. M.Guo, P.Chen, N.Yosri, et al., "Detection of heavy metals in food and agricultural products by surface-enhanced Raman spectroscopy," Food Rev. Int. https://doi.org/10.1080/ 87559129.2021.1934005.

[31] H. Tang, C. Zhu, G. Meng, and N. Wu, "Review-surfaceenhanced Raman scattering sensors for food safety and environmental monitoring,"J. Electrochem. Soc., vol. 165, no. 8, pp. 3098-3118, 2018.

[32] J. Choi, J. H. Kim, J. W. Oh, and J. M. Nam, "Surface-enhanced Raman scattering-based detection of hazardous chemicals in various phases and matrices with plasmonic nanostructures," Nanoscale, vol. 11, no. 43, pp. 20379-20391, 2019.

[33] W. Li, L. F. Li, Y. Zhang, X. N. Wang, and Y. Ozaki, “Recent advances in surface-enhanced Raman scattering-based sensors for the detection of inorganic ions: sensing mechanism and beyond," J. Raman Spectrosc., vol. 52, no. 2, pp. 1-14, 2020.

[34] D. R. Zhang, H. B. Pu, L. J. Huang, and D. W. Sun, “Advances in flexible surface-enhanced Raman scattering (SERS) substrates for nondestructive food detection: fundamentals and recent applications," Trends Food Sci. Technol., vol. 109, pp. 163-166, 2021.

[35] S. D. Christesen, "Raman cross sections of chemical agents and simulants," Appl. Spectrosc., vol. 42, no. 2, pp. 318-321, 1988.

[36] M. Fleischmann, P. J. Hendra, and A. J. Mcquillan, "Raman spectra of pyridine adsorbed at a silver electrode," Chem. Phys. Lett., vol. 26, no. 2, pp. 163-166, 1974.

[37] H. B. Li, M. S. Wang, Y. H. Li, et al., "Adsorption characteristics of silver atoms and silver ions on silica surface in silver nanoparticle hydrosol system," Appl. Surf. Sci., vol. 562, p. 150168, 2021.
[38] K. Kneipp, H. Kneipp, I. Itzkan, R. R. Dasari, and M. S. Feld, "Ultrasensitive chemical analysis by Raman spectroscopy," Chem. Rev., vol. 99, no. 10, pp. 2957-2976, 1999.

[39] S. M. Berus, M. Adamczyk-Popławska, B. MtynarczykBonikowska, et al., "SERS-based sensor for the detection of sexually transmitted pathogens in the male swab specimens: a new approach for clinical diagnosis," Biosens. Bioelectron., vol. 189, p. 113358, 2021.

[40] S. S. Wen, X. W. Ma, H. Liu, et al., "Accurate monitoring platform for the surface catalysis of nanozyme validated by surfaceenhanced Raman-kinetics model," Anal. Chem., vol. 92, no. 17, pp. 11763-11770, 2020.

[41] M. Kerker, D. S. Wang, and H. Chew, "Surface enhanced Raman scattering (SERS) by molecules adsorbed at spherical particles: errata," Appl. Opt., vol. 19, no. 24, pp. 4159-4174, 1980.

[42] W. L. Barnes, A. Dereux, and T. W. Ebbesen, "Surface plasmon subwavelength optics," Nature, vol. 424, pp. 824-830, 2003.

[43] A. A.-P. Ramón and L.-M. Luis, "SERS detection of small inorganic molecules and ions," Angew. Chem. Int. Ed., vol. 51, no. 45, pp. 11214-11223, 2012.

[44] A. Synytsya, M. Judexova, D. Hoskovec, M. Miskovicova, and L. Petruzelk, "Raman spectroscopy at different excitation wavelengths (1064, 785 and $532 \mathrm{~nm}$ ) as a tool for diagnosis of colon cancer," J. Raman Spectrosc., vol. 45, no. 10, pp. 903-911, 2014.

[45] G. H. Yao and Q. Huang, "DFT and SERS study of l-Cysteine adsorption on the surface of gold nanoparticles," J. Phys. Chem. C, vol. 122, no. 27, pp. 15241-15251, 2018.

[46] M. M. Veiga, J. A. Meech, and N. Oñate, "Mercury pollution from deforestation," Nature, vol. 368, no. 6474, pp. 816-817, 1994.

[47] B. Sun, X. Jiang, H. Wang, et al., "Surface-enhancement Raman scattering sensing strategy for discriminating trace mercuric ion (II) from real water samples in sensitive, specific, recyclable, and reproducible manners," Anal. Chem., vol. 87, no. 2, pp. 1250-1256, 2015.

[48] T. Kang, S. M. Yoo, I. Yoon, et al., "Au nanowire-on-film SERRS sensor for ultrasensitive $\mathrm{Hg}^{2+}$ detection," Chem. Eur. J., vol. 17, no. 7, pp. 2211-2214, 2011.

[49] X. Ding, L. Kong, J. Wang, F. Fang, D. Li, and J. Liu, "Highly sensitive SERS detection of $\mathrm{Hg}^{2+}$ ions in aqueous media using gold nanoparticles/graphene heterojunctions," ACS Appl. Mater. Interfaces, vol. 5, no. 15, pp. 7072-7078, 2013.

[50] M. Liu, Z. Wang, S. Zong, et al., "SERS detection and removal of mercury(II)/silver(I) using oligonucleotide-functionalized core/ shell magnetic silica sphere@Au nanoparticles," ACS Appl. Mater. Interfaces, vol. 6, no. 10, pp. 7371-7379, 2014.

[51] M. P. Cecchini, V. A. Turek, A. Demetriadou, G. Britovsek, and J. B. Edel, "Heavy metal sensing using self-assembled nanoparticles at a liquid-liquid interface," Adv. Opt. Mater., vol. 2, no. 10, pp. 966-977, 2014.

[52] T. Senapati, D. Senapati, A. K. Singh, Z. Fan, R. Kanchanapally, and P. C. Ray, "Highly selective SERS probe for $\mathrm{Hg}$ (II) detection using tryptophan-protected popcorn shaped gold nanoparticles," Chem. Commun., vol. 47, no. 37, pp. 10326-10328, 2011.

[53] S. Fu, X. Guo, H. Wang, T. Yang, Y. Wen, and H. Yang, "Detection of trace mercury ions in water by a novel Raman probe," Sens. Actuators, B, vol. 199, pp. 108-114, 2014.

[54] Q. Zhao, H. Zhang, H. Fu, Y. Wei, and W. Cai, "Raman reporterassisted Au nanorod arrays SERS nanoprobe for ultrasensitive 
detection of mercuric ion $\left(\mathrm{Hg}^{2+}\right)$ with superior anti-interference performances," J. Hazard Mater., vol. 398, p. 122890, 2020.

[55] X. Y. Guo, F. Chen, F. Wang, et al., "Recyclable Raman chip for detection of trace mercury ions," Chem. Eng. J., vol. 390, p. 124528, 2020.

[56] L. Chen, Y. Zhao, Y. Wang, et al., "Mercury species induced frequency-shift of molecular orientational transformation based on SERS," Analyst, vol. 141, pp. 4782-4788, 2016.

[57] W. Ma, M. Sun, L. Xu, L. Wang, H. Kuang, and C. Xu, “A SERS active gold nanostar dimer for mercury ion detection," Chem. Commun., vol. 49, no. 44, pp. 4989-4991, 2013.

[58] L. Xu, H. Yin, W. Ma, H. Kuang, L. Wang, and C. Xu, "Ultrasensitive SERS detection of mercury based on the assembled gold nanochains," Biosens. Bioelectron., vol. 67, pp. 472-476, 2015.

[59] S. Li, L. Xu, W. Ma, H. Kuang, L. Wang, and C. Xu, "Triple Raman label-encoded gold nanoparticle trimers for simultaneous heavy metal ion detection," Small, vol. 11, no. 28, pp. 3435-3439, 2015.

[60] D. Han, S. Y. Lim, B. J. Kim, L. Piao, and T. D. Chung, "Mercury(II) detection by SERS based on a single gold microshell," Chem. Commun., vol. 46, no. 30, pp. 5587-5589, 2010.

[61] Y. Lu, J. Zhong, G. Yao, and Q. Huang, “A label-free SERS approach to quantitative and selective detection of mercury (II) based on DNA aptamer-modified $\mathrm{SiO}_{2} @ A$ core/shell nanoparticles," Sens. Actuators, B, vol. 258, pp. 365-372, 2018.

[62] Y. Kang, T. Wu, B. Liu, X. Wang, and Y. Du, "Selective determination of mercury(II) by self-referenced surfaceenhanced Raman scattering using dialkyne-modified silver nanoparticles," Microchim. Acta, vol. 181, nos 11-12, pp. 1333-1339, 2014.

[63] C. Y. Song, B. Y. Yang, Y. Zhu, Y. J. Yang, and L. H. Wang, "Ultrasensitive sliver nanorods array SERS sensor for mercury ions," Biosens. Bioelectron., vol. 87, pp. 59-65, 2017.

[64] X. Yang, Y. He, X. L. Wang, and R. Yuan, "A SERS biosensor with magnetic substrate $\mathrm{CoFe}_{2} \mathrm{O}_{4} @ A g$ for sensitive detection of $\mathrm{Hg}^{2+}$," Appl. Surf. Sci., vol. 416, pp. 581-586, 2017.

[65] Y. Du, R. Liu, B. Liu, S. Wang, M. Y. Han, and Z. Zhang, "Surfaceenhanced Raman scattering chip for femtomolar detection of mercuric Ion (II) by ligand exchange," Anal. Chem., vol. 85, no. 6, pp. 3160-3165, 2013.

[66] Y. Zhao, Y. Yamaguchi, Y. Ni, M. Li, and X. Dou, “A SERS-based capillary sensor for the detection of mercury ions in environmental water," Spectrochim. Acta, Part A, vol. 233, p. 118193, 2020.

[67] W. Ren, C. Zhu, and E. Wang, "Enhanced sensitivity of a direct SERS technique for $\mathrm{Hg}^{2+}$ detection based on the investigation of the interaction between silver nanoparticles and mercury ions," Nanoscale, vol. 4, no. 19, pp. 5902-5909, 2012.

[68] B. Q. Hao, X. F. Bu, J. W. Wu, et al., "Determination of $\mathrm{Hg}^{2+}$ in water based on acriflavine functionalized AgNPs by SERS," Microchem. J., vol. 155, p. 104736, 2020.

[69] F. Liu, Y. Lou, X. Shi, H. Wang, and X. Zhu, "Preparation and characterization of monoclonal antibody specific for copperchelate complex," J. Immunol. Methods, vol. 387, nos 1-2, pp. 228-236, 2013.

[70] C. N. Hancock, L. H. Stockwin, B. Han, et al., “A copper chelate of thiosemicarbazone NSC 689534 induces oxidative/ER stress and inhibits tumor growth in vitro and in vivo," Free Radic. Biol. Med., vol. 50, no. 1, pp. 110-121, 2011.
[71] S. Sarkar, M. Pradhan, A. K. Sinha, M. Basu, and T. Pal, "Selective and sensitive recognition of $\mathrm{Cu}^{2+}$ in an aqueous medium: a surface-enhanced Raman scattering (SERS)-based analysis with a low-cost Raman reporter," Chem. Eur. J., vol. 18, pp. 6335-6342, 2012.

[72] P. Ndokoye, J. Ke, J. Liu, Q. Zhao, and X. Li, “l-cysteine-modified gold nanostars for SERS-based copper ions detection in aqueous media," Langmuir, vol. 30, no. 44, pp. 13491-13497, 2014.

[73] W. Q. Tang, B. D. Chase, D. L. Sparks, and J. F. Rabolt, "Selective and quantitative detection of trace amounts of mercury(II) Ion $\left(\mathrm{Hg}^{2+}\right)$ and copper(II) ion $\left(\mathrm{Cu}^{2+}\right)$ using surface-enhanced Raman scattering (SERS)," Appl. Spectrosc., vol. 69, no. 7, pp. 843-849, 2015.

[74] V. M. Zamarion, R. A. Timm, K. Araki, and H. E. Toma, "Ultrasensitive SERS nanoprobes for hazardous metal ions based on trimercaptotriazine-modified gold nanoparticles," Inorg. Chem., vol. 47, no. 8, pp. 2934-2936, 2008.

[75] V. M. Szlag, S. R. Rodriguez, J. Y. He, et al., "Molecular affinity agents for intrinsic surface-enhanced Raman scattering (SERS) sensors," ACS Appl. Mater. Interfaces, vol. 10, no. 38, pp. 31825-31844, 2018.

[76] P. Pinkhasova, L. Yang, Y. Zhang, S. Sukhishvili, and H. Du, "Differential SERS activity of gold and silver nanostructures enabled by adsorbed poly(vinylpyrrolidone)," Langmuir, vol. 28, no. 5, pp. 2529-2535, 2012.

[77] S. Xu, X. Cao, and Y. Zhou, "Polyvinylpyrrolidine-functionalized silver nanoparticles for SERS based determination of copper(II)," Microchim. Acta, vol. 186, no. 8, pp. 562-567, 2019.

[78] Y. Wang, Z. Su, L. Wang, et al., "SERS assay for copper(II) ions based on dual hot-spot model coupling with MarR protein: new $\mathrm{Cu}^{2+}$-specific biorecognition element," Anal. Chem., vol. 89, no. 12, pp. 6392-6398, 2017.

[79] Y. Liu, Y. Wu, X. Guo, Y. Wen, and H. Yang, “Rapid and selective detection of trace $\mathrm{Cu}^{2+}$ by accumulation-reaction-based Raman spectroscopy," Sens. Actuators, B, vol. 283, pp. 278-283, 2019.

[80] T. V. Tikhonova, D. Y. Sorokin, W. R. Hagen, M. G. Khrenova, and V. O. Popov, "Trinuclear copper biocatalytic center forms an active site of thiocyanate dehydrogenase," Proc. Natl. Acad. Sci. Unit. States Am., vol. 117, no. 10, pp. 5280-5290, 2020.

[81] P. Zhu, Y. Wang, G. Li, et al., "Preparation and application of a chemically modified laccase and copper phosphate hybrid flower-like biocatalyst," Biochem. Eng. J., vol. 144, pp. 235-243, 2019.

[82] C. N. Li, H. X. Ouyang, X. P. Tang, G. Q. Wen, A. H. Liang, and Z. L. Jiang, “A surface enhanced Raman scattering quantitative analytical platform for detection of trace $\mathrm{Cu}$ coupled the catalytic reaction and gold nanoparticle aggregation with labelfree victoria blue B molecular probe," Biosens. Bioelectron., vol. 87, pp. 888-893, 2017.

[83] S. Acharyya, P. Chakraborty, S. Lahiri, B. Raymahashay, and S. Guha, "Arsenic poisoning in the Ganges delta," Nature, vol. 401, p. 545, 1999.

[84] M. Kim, H. J. Um, S. Bang, et al., "Arsenic removal from Vietnamese groundwater using the arsenic-binding DNA aptamer," Environ. Sci. Technol., vol. 43, no. 24, pp. 9335-9340, 2009.

[85] A. H. Smith, C. Hopenhayn-Rich, M. N. Bates, et al., "Cancer risks from arsenic in drinking water," Environ. Health Perspect., vol. 97, pp. 259-267, 1992. 
[86] R. Haque, D. N. G. Mazumder, S. Samanta, et al., "Arsenic in drinking water and skin lesions: dose-response data from West Bengal, India," Epidemiology, vol. 14, no. 2, pp. 174-182, 2003.

[87] D. Mohan and C. U. Pittman, "Arsenic removal from water/ wastewater using adsorbents-a critical review," J. Hazard Mater., vol. 142, nos 1-2, pp. 1-53, 2007.

[88] P. L. Smedley and D. G. Kinniburgh, "A review of the source, behaviour and distribution of arsenic in natural waters," Appl. Geochem., vol. 17, no. 5, pp. 517-528, 2002.

[89] P. Wang, G. Sun, Y. Jia, A. A. Meharg, and Y. Zhu, "A review on completing arsenic biogeochemical cycle: microbial volatilization of arsines in environment," J. Environ. Sci., vol. 26, no. 2, pp. 37-381, 2014.

[90] J. Hao, M. J. Han, S. Han, X. Meng, T. L. Su, and Q. K. Wang, "SERS detection of arsenic in water: a review," J. Environ. Sci., vol. 36, no. 10, pp. 152-162, 2015.

[91] M. Mulvihill, A. Tao, K. Benjauthrit, J. Arnold, and P. Yang, "Surface-enhanced Raman spectroscopy for trace arsenic detection in contaminated water," Angew. Chem. Int. Ed., vol. 47, no. 34, pp. 6456-6460, 2008.

[92] M. J. Han, J. Hao, Z. Xu, and X. Meng, "Surface-enhanced Raman scattering for arsenate detection on multilayer silver nanofilms," Anal. Chim. Acta, vol. 692, nos 1-2, pp. 96-102, 2011.

[93] C. Chen, J. Hao, L. Zhu, et al., "Direct two-phase interfacial selfassembly of aligned silver nanowire films for surface enhanced Raman scattering applications," J. Mater. Chem. A, vol. 1, no. 43, pp. 13496-13501, 2013.

[94] J. Du, J. Cui, and C. Jing, "Rapid in situ identification of arsenic species using a portable $\mathrm{Fe}_{3} \mathrm{O}_{4} @ \mathrm{Ag}$ SERS sensor," Chem. Commun., vol. 50, no. 3, pp. 347-349, 2014.

[95] S. Xu, F. P. Sabino, A. Janotti, D. B. Chase, and J. F. Rabolt, “A unique surface-enhanced Raman scattering (SERS) substrate for the study of arsenic speciation and detection," J. Phys. Chem. A, vol. 122, no. 49, pp. 9474-9482, 2018.

[96] J. L. Li, L. X. Chen, T. T. Lou, and Y. Q. Wang, "Highly sensitive SERS detection of $\mathrm{As}^{3+}$ ions in aqueous media using glutathione functionalized silver nanoparticles," ACS Appl. Mater. Interfaces, vol. 3, no. 10, pp. 3936-3941, 2011.

[97] N. Qi, B. W. Li, H. Y. You, et al., "Surface-enhanced Raman scattering on a zigzag microfluidic chip: towards highsensitivity detection of As(III) ions," Anal. Methods, vol. 6, no. 12, pp. 4077-4082, 2014.

[98] X. Fang and W. Tan, "Aptamers generated from cell-SELEX for molecular medicine: a chemical biology approach," Acc. Chem. Res., vol. 43, no. 1, pp. 48-57, 2010.

[99] L. Ye, G. Wen, J. Dong, et al., “A simple label-free rhodamine 6G SERS probe for quantitative analysis of trace As(III) in the aptamernanosol," RSC Adv., vol. 4, no. 62, pp. 32960-32964, 2014.

[100] B. Yang, X. Chen, R. Liu, B. Liu, and C. Jiang, "Target induced aggregation of modified Au@Ag nanoparticles for surface enhanced Raman scattering and its ultrasensitive detection of arsenic(III) in aqueous solution," RSC Adv., vol. 5, no. 95, pp. 77755-77759, 2015.

[101] A. O. Barimah, Z. M. Guo, A. A. Agyekum, et al., "Sensitive labelfree $\mathrm{Cu}_{2} \mathrm{O} / \mathrm{Ag}$ fused chemometrics SERS sensor for rapid detection of total arsenic in tea," Food Control, vol. 130, p. 108341, 2021.

[102] C. J. Frederickson, J. Y. Koh, and A. I. Bush, "The neurobiology of zinc in health and disease," Nat. Rev. Neurosci., vol. 6, no. 6, pp. 449-462, 2005.
[103] J. M. Berg and Y. G. Shi, "The galvanization of biology: a growing appreciation for the roles of zinc," Science, vol. 271, no. 5252, pp. 1061-1065, 1996.

[104] L. A. Finney and T. V. O'Halloran, "Transition metal speciation in the cell: insights from the chemistry of metal ion receptors," Science, vol. 300, no. 5621, pp. 931-937, 2003.

[105] A. M. Mahmoud, U. Al-Alem, E. Shah, K. Batai, and R. Kittles, "Zinc and prostate cancer: a systematic review," Cancer Res., vol. 73, 2013, 4883.

[106] M. Schrag, A. Crofton, M. Zabel, et al., "Effect of cerebral amyloid angiopathy on brain iron, copper, and zinc in Alzheimer's disease," J. Alzheim. Dis., vol. 24, no. 1, pp. 137-149, 2011.

[107] O. Barbier, G. Jacquillet, M. Tauc, M. Cougnon, and P. Poujeol, "Effect of heavy metals on, and handling by, the kidney," Nephron. Physiol., vol. 99, no. 4, pp. 105-110, 2005.

[108] T. Cheng, Y. Xu, S. Zhang, W. Zhu, X. Qian, and L. Duan, “A highly sensitive and selective off-on fluorescent sensor for cadmium in aqueous solution and living cell," J. Am. Chem. Soc., vol. 130, no. 48, pp. 16160-16161, 2008.

[109] L. Szabó, L. F. Leopold, B. I. Cozar, N. Leopold, K. Herman, and V. Chi, "SERS approach for Zn(II) detection in contaminated soil," Cent. Eur. J. Chem., vol. 9, no. 3, pp. 410-414, 2011.

[110] L. Jin, G. She, L. Mu, and W. Shi, "Highly uniform indicatormediated SERS sensor platform for the detection of $\mathrm{Zn}^{2+}$," RSC Adv., vol. 6, no. 20, pp. 16555-16560, 2016.

[111] H. Zhuang, Z. Wang, X. Zhang, J. A. Hutchison, and M. Li, “A highly sensitive SERS-based platform for $\mathrm{Zn}$ (II) detection in cellular media," Chem. Commun., vol. 53, no. 11, pp. 1797-1800, 2017.

[112] K. Komatsu, K. Kikuchi, H. Kojima, Y. Urano, and T. Nagano, "Selective zinc sensor molecules with various affinities for $\mathrm{Zn}^{2+}$, revealing dynamics and regional distribution of synaptically released $\mathrm{Zn}^{2+}$ in hippocampal slices," J. Am. Chem. Soc., vol. 127, no. 29, pp. 10197-10204, 2015.

[113] S. Maruyama, K. Kikuchi, T. Hirano, Y. Urano, and T. Nagano, “A novel, cell-permeable, fluorescent probe for ratiometric imaging of zinc ion," J. Am. Chem. Soc., vol. 124, no. 36, pp. 10650-10651, 2002.

[114] N. Lee, N. H. Ly, J. S. Kim, H. S. Jung, and S. W. Joo, "A selective triarylmethine-based spectroscopic probe for $\mathrm{Zn}^{2+}$ ion monitoring," Dyes Pigm., vol. 171, p. 107721, 2019.

[115] Y. Teng, Z. Ren, Y. Zhang, Z. Wang, and Y. She, "Determination of prostate cancer marker $\mathrm{Zn}^{2+}$ with a highly selective surface-enhanced Raman scattering probe on liquid-liquid self-assembled Au nanoarrays," Talanta, vol. 209, p. 120569, 2020.

[116] J. Yin, T. Wu, J. Song, et al., "SERS-active nanoparticles for sensitive and selective detection of cadmium ion $\left(\mathrm{Cd}^{2+}\right)$," Chem. Mater., vol. 23, no. 21, pp. 4756-4764, 2011.

[117] S. S. R. Dasary, Y. K. Jones, S. L. Barnes, P. C. Ray, and A. K. Singh, "Alizarin reporter based ultrasensitive plasmonic SERS probe for trace level cadmium detection in drinking water," Sens. Actuators, B, vol. 224, pp. 65-72, 2016.

[118] J. J. Dua and C. Y. Jing, "One-step fabrication of dopamineinspired Au for SERS sensing of $\mathrm{Cd}^{2+}$ and polycyclic aromatic hydrocarbons," Anal. Chim. Acta, vol. 1062, pp. 131-139, 2019. 
[119] S. Thatai, P. Khurana, S. Prasad, and D. Kumar, "Plasmonic detection of $\mathrm{Cd}^{2+}$ ions using surface-enhanced Raman scattering active core-shell nanocomposite," Talanta, vol. 134, pp. 568-575, 2015.

[120] A. R. Flegal and D. R. Smith, "Current needs for increased accuracy and precision in measurements of low levels of lead in blood,” Environ. Res., vol. 58, no. 2, pp. 125-133, 1992.

[121] P. Chooto, P. Wararatananurak, and C. Innuphat, "Determination of trace levels of $\mathrm{Pb}(\mathrm{II})$ in tap water by anodic stripping voltammetry with boron-doped diamond electrode," Sci. Asia, vol. 36, no. 2, pp. 150-156, 2010.

[122] K. S. Subramanian and G. V. Iyengar, "Environmental lead: need for reference materials,” Fresenius'). Anal. Chem., vol. 352, nos 1-2, pp. 232-235, 1995.

[123] S. W. Santoro and G. F. Joyce, "A general purpose RNA-cleaving DNA enzyme," Proc. Natl. Acad. Sci. Unit. States Am., vol. 94, no. 9, pp. 4262-4266, 1997.

[124] A. Tian, Y. Liu, and J. Gao, "Sensitive SERS detection of lead ions via DNAzyme based quadratic signal amplification," Talanta, vol. 171, pp. 185-189, 2017.

[125] C. Fu, W. Xu, H. Wang, et al., "DNAzyme-based plasmonic nanomachine for ultrasensitive selective surface-enhanced Raman scattering detection of lead ions via a particle-on-a-film hot spot construction," Anal. Chem., vol. 86, no. 23, pp. 11494-11497, 2014.

[126] Y. Wang and J. Irudayaraj, "A SERS DNAzyme biosensor for lead ion detection," Chem. Commun., vol. 47, no. 15, pp. 4394-4396, 2011.

[127] Y. Shi, H. Wang, X. Jiang, et al., "Ultrasensitive, specific, recyclable, and reproducible detection of lead ions in real systems through a polyadenine-assisted, surface-enhanced Raman scattering silicon chip," Anal. Chem., vol. 88, no. 7, pp. 3723-3729, 2016.

[128] W. Xu, A. Zhao, F. Zuo, R. Khan, and J. Li, "A highly sensitive DNAzyme-based SERS biosensor for quantitative detection of lead ions in human serum," Anal. Bioanal. Chem., vol. 412, no. 13, pp. 4565-4574, 2020.

[129] M. S. Frost, M. J. Dempsey, and D. E. Whitehead, "Highly sensitive SERS detection of $\mathrm{Pb}^{2+}$ ions in aqueous media using citrate functionalised gold nanoparticles," Sens. Actuators, $B$, vol. 221, pp. 1003-1008, 2015.

[130] Z. Zhang, P. Ma, J. Li, Y. Sun, and H. Chen, "Colorimetric and SERS dual-mode detection of lead ions based on Au-Ag core-shell nanospheres: featuring quick screening with ultra-high sensitivity," Opt Express, vol. 27, no. 20, pp. 29248-29260, 2019.

[131] Z. Xu, L. W. Zhang, B. Mei, et al., "A rapid surface-enhanced Raman scattering (SERS) method for $\mathrm{Pb}^{2+}$ detection using l-cysteine-modified Ag-coated Au nanoparticles with core-shell nanostructure," Coatings, vol. 8, no. 11, p. 394, 2018.

[132] X. Shi, W. Gu, C. Zhang, L. Zhao, and Y. Xian, "Construction of a graphene/Au-nanoparticles/cucurbit[7]uril-based sensor for $\mathrm{Pb}^{2+}$ sensing," Chem. Eur. J., vol. 22, no. 16, pp. 5643-5648, 2016.

[133] H. Ouyang, S. Ling, A. Liang, and Z. Jiang, "A facile aptamerregulating gold nanoplasmonic SERS detection strategy for trace lead ions," Sens. Actuators, B, vol. 258, pp. 739-744, 2018.

[134] C. N. Li, P. D. Fan, A. H. Liang, Q. Y. Liu, and Z. L. Jiang, “Aptamer based determination of $\mathrm{Pb}(\mathrm{II})$ by SERS and by exploiting the reduction of $\mathrm{HAuCl}_{4}$ by $\mathrm{H}_{2} \mathrm{O}_{2}$ as catalyzed by graphene oxide nanoribbons," Microchim. Acta, vol. 185, pp. 177-184, 2018.

[135] L. Zhao, W. Gu, C. Zhang, X. Shi, and Y. Xian, "In situ regulation nanoarchitecture of Au nanoparticles/reduced graphene oxide colloid for sensitive and selective SERS detection of lead ions," J. Colloid Interface Sci., vol. 465, pp. 279-285, 2016.

[136] Y. Ye, H. Liu, L. Yang, and J. Liu, "Sensitive and selective SERS probe for trivalent chromium detection using citrate attached gold nanoparticles," Nanoscale, vol. 4, no. 20, pp. 6442-6448, 2012.

[137] P. Biswas, A. K. Karn, P. Balasubramanian, and P. G. Kale, "Biosensor for detection of dissolved chromium in potable water: a review," Biosens. Bioelectron., vol. 94, pp. 589-604, 2017.

[138] J. Du and C. Jing, "Preparation of $\mathrm{Fe}_{3} \mathrm{O}_{4} @ \mathrm{Ag}$ SERS substrate and its application in environmental $\mathrm{Cr}(\mathrm{VI})$ analysis," J. Colloid Interface Sci., vol. 358, no. 1, pp. 54-61, 2011.

[139] B. Lv, Z. Sun, J. Zhang, and C. Jing, "Multifunctional satellite $\mathrm{Fe}_{3} \mathrm{O}_{4}$-Au@ @TiO ${ }_{2}$ nano-structure for SERS detection and photoreduction of $\mathrm{Cr}(\mathrm{VI})$," Colloid. Surface. Physicochem. Eng. Aspect., vol. 513, pp. 234-240, 2017.

[140] W. Ji, Y. Wang, I. Tanabe, X. Han, B. Zhao, and Y. Ozaki, "Semiconductor-driven "turn-off" surface-enhanced Raman scattering spectroscopy: application in selective determination of chromium( VI ) in water," Chem. Sci., vol. 6, no. 1, pp. 342-348, 2015.

[141] W. Zhou, B. C. Yin, and B. C. Ye, "Highly sensitive surfaceenhanced Raman scattering detection of hexavalent chromium based on hollow sea urchin-like $\mathrm{TiO}_{2} @$ Ag nanoparticle substrate," Biosens. Bioelectron., vol. 87, pp. 187-194, 2017.

[142] X. F. Bu, Z. Y. Zhang, L. X. Zhang, et al., "Highly sensitive SERS determination of chromium(VI) in water based on carbimazole functionalized alginate-protected silver nanoparticles," Sens. Actuators, B, vol. 273, pp. 1519-1524, 2018.

[143] Y. Guo, D. Li, S. Zheng, N. Xu, and W. Deng, "Utilizing Ag-Au core-satellite structures for colorimetric and surface-enhanced Raman scattering dual-sensing of Cu (II)," Biosens. Bioelectron., vol. 159, p. 112192, 2020.

[144] L. Dan, M. Yadan, D. Huazhen, J. Fei, D. Wei, and R. Xingang, "Fluorescent/SERS dual-sensing and imaging of intracellular $\mathrm{Zn}^{2+}$," Anal. Chim. Acta, vol. 1038, pp. 148-156, 2018.

[145] P. Makam, R. Shilpa, A. E. Kandjani, S. R. Periasamy, and T. Govindaraju, "SERS and fluorescence-based ultrasensitive detection of mercury in water," Biosens. Bioelectron., vol. 100, pp. 556-564, 2018.

[146] P. Makam, R. Shilpa, A. E. Kandjani, et al., “Colorimetric/ fluorescent/SERS triple-channel sensing of $\mathrm{Cu}^{2+}$ in real systems based on chelation-trigged self-aggregation," Chem. Eng. J., vol. 399, p. 125840, 2020.

[147] J. Wang, W. Ahmad, H. M. Mehedi, et al., “Landing microextraction sediment phase onto surface enhanced Raman scattering to enhance sensitivity and selectivity for chromium speciation in food and environmental samples," Food Chem., vol. 323, p. 126812, 2020.

[148] Y. Shi, N. Chen, Y. Y. Su, H. Y. Wang, and Y. He, "Silicon nanohybrid-based SERS chips armed with an internal standard for broad-range, sensitive and reproducible simultaneous quantification of lead(II) and mercury(II) in real systems," Nanoscale, vol. 10, no. 8, pp. 4010-4018, 2018. 